This PDF is a selection from a published volume from the National Bureau of Economic Research

Volume Title: Housing and the Financial Crisis

Volume Author/Editor: Edward L. Glaeser and Todd Sinai, editors

Volume Publisher: University of Chicago Press

Volume ISBN: 978-0-226-03058-6

Volume URL: http://www.nber.org/books/glae11-1

Conference Date: November 17-18, 2011

Publication Date: August 2013

Chapter Title: House Price Moments in Boom-Bust Cycles

Chapter Author(s): Todd Sinai

Chapter URL: http://www.nber.org/chapters/c12619

Chapter pages in book: (p. 19 - 68) 


\title{
House Price Moments in Boom-Bust Cycles
}

\author{
Todd Sinai
}

The United States experienced a remarkable boom and bust in house prices in the 2000s. According to the Fiserv Case-Shiller ten-city index, house prices grew by 125 percent in real terms from their trough in 1996 to their peak in 2006 and subsequently fell by 38 percent over the next five years. The impacts of this house price cycle have been wide-ranging and severe.

Explaining the causes of this episode of house price growth and decline and its effects on the rest of the banking sector and the real economy is the subject of much current research, some of which is collected in this volume. Potential explanations of the boom and bust in house prices include changing interest rates, subprime lending, irrational exuberance on the part of home buyers, a shift to speculative investment in housing, contagion and fads, and international capital flows. ${ }^{1}$

Todd Sinai is associate professor of real estate and business economics and public policy at the Wharton School at the University of Pennsylvania and a research associate of the National Bureau of Economic Research.

This chapter was prepared for the NBER's "Housing and the Financial Crisis" conference on November 17 and 18, 2011. I am grateful to Karl Case, Ed Glaeser, Charles Himmelberg, the conference participants, and the two book reviewers for their helpful comments and to Gordon MacDonald for his excellent research assistance. The Research Sponsors' Program of the ZellLurie Real Estate Center at Wharton and the Smith-Richardson Foundation provided financial support. For acknowledgments, sources of research support, and disclosure of the author's material financial relationships, if any, please see http://www.nber.org/chapters/c12619.ack.

1. A complete set of references for the potential causes of the house price boom in the $2000 \mathrm{~s}$ is beyond the scope of this article. However, an interested reader might find the following citations of use. For discussions of the explanatory potential of interest rates, see Glaeser, Gottlieb, and Gyourko (2010); Himmelberg, Mayer, and Sinai (2005); Mayer and Sinai (2009); and Campbell et al. (2009). For subprime lending, see Pavlov and Wachter (2009); Mian and Sufi (2009); Wheaton and Nechayev (2008); and Lai and Van Order (2010). Arguments in favor of irrational bubbles can be found in Case and Shiller (2003) and Shiller (2005, 2006). Barlevy and Fisher (2011); Bayer, Geissler, and Roberts (2011); and Robinson and Todd (2010) examine the issue 
The goal of this chapter is to describe a set of patterns in house prices among housing markets in the United States and to compile a set of empirical facts that potential explanations of the housing boom and bust should seek to explain. While some of the empirical relationships detailed here have been discussed to varying degrees in prior research, this paper seeks to assemble a broad collection of empirical facts. A unified theory of housing booms and busts would presumably be able to explain the entire set of facts. Of course, it is possible that there is no single mechanism that generated all the economic fluctuations that were experienced, and that a combination of causes needs to be explored.

For this chapter, I consider only house price dynamics. Evaluating the many potential determinants of these housing market dynamics is generally outside the scope of this chapter. However, the role of demand fundamentals, such as rents, income, and employment, is lightly addressed. Other potentially important contributors to housing market dynamics are the purview of other authors in this volume, such as Haughwought et al.'s chapter on the supply side of housing markets; Glaeser, Gottlieb, and Gyourko's chapter on interest rates; and Keys et al.'s chapter on housing finance. In addition, I broadly define housing markets as metropolitan statistical areas (MSAs), intended to correspond to labor market areas that workers are willing to commute amongst. During the boom-bust, there were also important within-MSA house price dynamics. These dynamics are addressed by Genesove and Han in this volume as well as Ferreira and Gyourko (2011) and Bayer, Geissler, and Roberts (2011). ${ }^{2}$

I highlight six stylized facts. First, despite the sizable boom-bust pattern in house prices at the national level, individual housing markets in the United States experienced considerable heterogeneity in the amplitudes of their cycles. The seventy-fifth percentile MSA experienced 111 percent troughto-peak growth in real house prices in the 1990s and 2000s (using Federal Housing Finance Agency [FHFA] data), whereas the twenty-fifth percentile MSA had only 32 percent trough-to-peak real house price growth.

Second, the boom-bust of the 2000s bears remarkable similarities-as well as some differences - to the boom-bust of the 1980s. We observe two types of MSAs in the data. One set experienced house price cycles in both the 1980s and the 2000s, whereas the other set experienced a boom-bust only in the 2000s. The MSA-level correlation in trough-to-peak real house price growth in the late 1980s and the early 2000s for all MSAs is quite high

of speculative investment demand contributing to house price booms. Burnside, Eichenbaum, and Rebelo (2011) consider contagion ("social dynamics") and fads. Favilukis, Ludvigson, and Van Nieuwerburgh (2011) show that foreign capital flows into the United States could, in general equilibrium, lead to increases in the price-to-rent ratio for owner-occupied houses that match the aggregate US time series.

2. I also limit my attention to US housing markets. Burnside, Eichenbaum, and Rebelo (2011) document house price dynamics in eighteen Organization for Economic Cooperation and Development (OECD) countries. 
at 0.45 and would be higher still if those MSAs that did not experience a 1980s cycle at all were excluded.

Third, housing markets also experienced differences in the timing of their cycles. Most MSAs in the 1990s saw their house prices bottom either between 1990 and 1993 or between 1996 and 1997, and house prices generally peaked in 2006 and 2007. In the 1980s, house prices peaked between 1986 and 1990. Potential explanations for housing booms, therefore, need to generate both differences in the amplitude and timing of price changes across MSAs.

Fourth, the largest booms and busts, and their timing, seem to be clustered geographically. The largest amplitude cycles in the boom/bust of the 1990s and 2000s occurred in coastal MSAs and in Florida. These geographic concentrations also had price peaks and troughs that started at similar times, but distinct from the rest of the country.

Fifth, other interesting patterns emerge when one considers annual house price growth, rather than house price changes from trough to peak and back again. In particular, the cross-sectional variance of annual house price changes increases in booms and decreases in busts.

Lastly, these five patterns remain even when house prices are purged of demand fundamentals such as rents, incomes, or employment. Although changes in fundamentals are correlated with changes in house prices, cycles in these fundamentals do not have the same amplitude as price cycles and the time pattern of the growth in fundamentals does not match the timing of the growth in house prices. In fact, controlling for demand fundamentals makes the remaining boom-bust patterns in house prices even starker.

Collectively, these facts limit the possible explanations of the housing boom and bust. The fact that changing demand fundamentals cannot match the boom/bust pattern of house prices indicates that the house price cycles were due to changes in the price of owning a home rather than changes in the underlying demand for a place to live. However, the factors that are commonly believed to determine asset prices - the cost of credit, changing growth expectations, or time-varying risk premia - often vary over time only at the national level and thus cannot account for the different magnitudes of the booms and busts across metropolitan areas. Some have postulated that a national factor, such as the availability of subprime mortgages, might interact with local characteristics, such as the elasticity of housing supply, to create different-sized booms across MSAs. However, those explanations do not address why the booms would start at different times in different MSAs. Another set of explanations postulate that idiosyncratic MSA-specific conditions, such as differential availability of subprime mortgages, an influx of speculators, or excessive optimism, led to booms in a subset of MSAs. However, the remarkable similarity between the location and size of the booms of the 1980s and 2000s implies that, for this to be explanation, those same conditions must have reoccurred in the same MSAs.

The remainder of this chapter proceeds as follows. I first describe the data 
used in the chapter and the algorithm for identifying peaks and troughs in each MSA's time series. In section 1.2, I describe the aggregate national patterns in house price dynamics. Section 1.3 makes the point that MSAs can vary considerably from the national average and documents heterogeneity in the amplitude of the housing boom/bust of the 1990s and 2000s. It also shows that house price booms were typically followed by house price busts. The similarities and differences between the housing boom of the 1980s and the boom of the 2000s is discussed in section 1.4. The next section documents the fact that MSA-level house prices hit their troughs and peaks in different years. Section 1.6 shows that MSAs with similar amplitudes and timing in their housing booms and busts are clustered near each other geographically. Section 1.7 moves from the trough-to-peak house price growth concept to consider annual growth in house prices and the distribution of that growth rate across MSAs. I briefly discuss housing demand fundamentals in section 1.8, finding that house price cycles remain even conditional on cycles in housing fundamentals. Finally, section 1.9 briefly concludes.

\subsection{Data}

The primary source of data is the FHFA's quarterly house price index from data on repeat sales of homes. By comparing repeat transactions on houses that sell multiple times, the index controls for the size or quality of the house to the extent that the house is not renovated. The most significant benefit of the data is that it is available over a very long time (it is reliable as early as 1980) and for a large number of MSAs. However, to be included in the index's sample, the houses need to actually transact - and multiple times at that - and have conforming mortgages securitized by Fannie Mae or Freddie Mac. This sample of houses may not be representative of the overall housing stock and may not reflect the full volatility of the underlying housing market. In addition, the FHFA indexes are normalized within each MSA and thus cannot be used for cross-MSA house price comparisons. The FHFA data contains 344 MSAs with data between 1990 and 2010 and 163 MSAs with data covering 1980 through 2010. I annualize the data by averaging the index over the four quarters in a calendar year and convert the price indexes from nominal to real terms by deflating using the Consumer Price Index (CPI) (all urban consumers).

The FHFA repeat sales index is augmented with rent data from Reis Inc. Reis surveys "class A" apartment buildings, which are typically among the nicest in a given market, and adjusts the rents for concessions, such as months of free rent, to calculate a measure of effective rent. This is the rent concept we use as a proxy for rental values of owner-occupied houses. Because the Reis and FHFA indexes measure two different quantities of housing - the housing stock comprised by the apartment buildings in the Reis data can be quite different than the housing stock in the single-family 
detached houses in the FHFA data-I will not try to interpret the differences in house price levels versus rents in a given MSA. Instead, in section 1.8, I will compare the growth in FHFA prices to the growth in Reis rents, which merely requires that the growth in rents for apartments tracks the growth in (unobserved) rental value of houses.

As an alternative to using apartment rents as a proxy for housing demand, one could use demand fundamentals. For that reason, I collect data on median per capita income by MSA and employment by MSA from the Bureau of Labor Statistics (BLS). Income is converted into real dollars using the CPI.

Much of the analysis in this chapter concerns the peaks and troughs of housing cycles. The algorithm to determine those troughs and peaks starts by determining the peak of house prices in the 2000s. For each MSA, that peak is defined by first finding all the local maxima - years where the average annual real house price exceeds that of the adjacent years - in the 1999 through 2010 period and then choosing the local maximum with the highest real house price. After that, the algorithm works backward in time: it finds the local minimum - a year where house prices are lower than in the adjacent years - in the period prior to the 2000s peak year that is closest in time to the 2000s peak year and calls it the 1990s trough. The next preceding local maximum is labeled the 1990 s peak, and the local minimum that precedes it is called the 1980s trough. Some MSAs do not have cyclical enough house prices for there to be local maxima and minima for all possible peaks and troughs. In those cases, the algorithm defines only those peaks and troughs it can identify. In addition, the trough in house prices in the $2000 \mathrm{~s}$ is defined as the lowest real house price subsequent to the 2000s peak. However, that so-called trough often occurs in 2010 , the last year of the data, and thus may not reflect the actual bottom in house prices. The peak/trough algorithm is repeated for all the MSA-level economic variables in the data set-house prices, apartment rents, median incomes, and MSA employment - as well as the ratios of house prices to rents, incomes, and employment. ${ }^{3}$

\subsection{National Patterns}

The history of national average house prices in the United States is by now well-known. According to data from the FHFA, real house prices rose more

3. Burnside, Eichenbaum, and Rebelo (2011) apply a related algorithm to house price data for eighteen countries. Two differences are that they smooth quarterly house price growth using a five-quarter moving average and they require the price change in a run-up to exceed a minimum bound before calling it a boom. Ferreira and Gyourko (2011) apply a more rigorous econometric procedure to identify house price troughs across US metropolitan areas and Census tracts from structural breaks in house price growth. Davidoff (2012) identifies house price peaks by choosing the date that minimizes the standard deviation in annual house price growth rates before and after the peak and estimates trough-to-peak house price growth by assuming fixed dates for the troughs. 
than 55 percent between the mid-1990s and the end of 2006 and had declined by almost 17 percent by late 2010. A national boom-bust in house prices also was experienced in the 1980s, with real prices rising nearly 15 percent between the mid-1980s and late 1989 and subsequently falling by 8 percent. This data is plotted in figure 1.1. The dashed line, labeled "HPI" (house price index) corresponds to the FHFA national series, deflated by the CPI, and is normalized so that it equals one in $1990 .{ }^{4}$

Another index, Fiserv Case-Shiller, uses a similar repeat-sales methodology but, unlike the FHFA index, is not limited to housing transactions with conforming mortgages and does not exclude sales of foreclosed homes. The real Fiserv Case-Shiller index is plotted in figure 1.1, in the dotted line, for comparison with the FHFA index. The Fiserv Case-Shiller index demonstrates substantially more volatility than the national FHFA index, more than doubling between 1997 and 2007 and subsequently falling by about one-third. However, the Fiserv Case-Shiller index in this figure is a composite of just ten cities, and it turns out that the differences in volatility between the FHFA index and the Case-Shiller index is more a function of the composition of cities that make up the index than of the composition of housing transactions within a city. ${ }^{5}$ To show this, we plot (with a dashdot line) a composite real FHFA index for the same ten cities that are in the Fiserv Case-Shiller ten-city composite index. The two ten-city indexes are quite similar, with the Fiserv Case-Shiller index exhibiting slightly more volatility. This chapter uses the FHFA series because the data covers a longer time span - for many MSAs, it starts (reliably) in 1980 rather than Fiserv Case-Shiller's 1987-and because it covers more metropolitan areas. However, based on figure 1.1, the results should be similar if other house price indexes are used.

\subsection{Heterogeneity in Amplitude}

The national pattern of house price dynamics masks considerable heterogeneity within the United States. One way to see this cross-MSA variation is to consider the amplitude of the trough-to-peak and peak-to-trough cycles in house prices experienced across various housing markets. Appendix Table A reports these statistics for each MSA in the data. In the 1990s and 2000s, most MSAs did not experience nearly the price growth reflected in the national average. However, a number of MSAs experienced considerably more growth, skewing the distribution of house price growth. The dispersion in the cumulative real price growth from each MSA's trough to peak is graphed in figure 1.2. For instance, the solid line plots a kernel estimate of the distribution of

4. These sorts of aggregate house price dynamics were initially modeled in a stock-flow framework, such as DiPasquale and Wheaton (1994).

5. The Fiserv Case-Shiller index is also publicly available as a twenty-city composite index. 


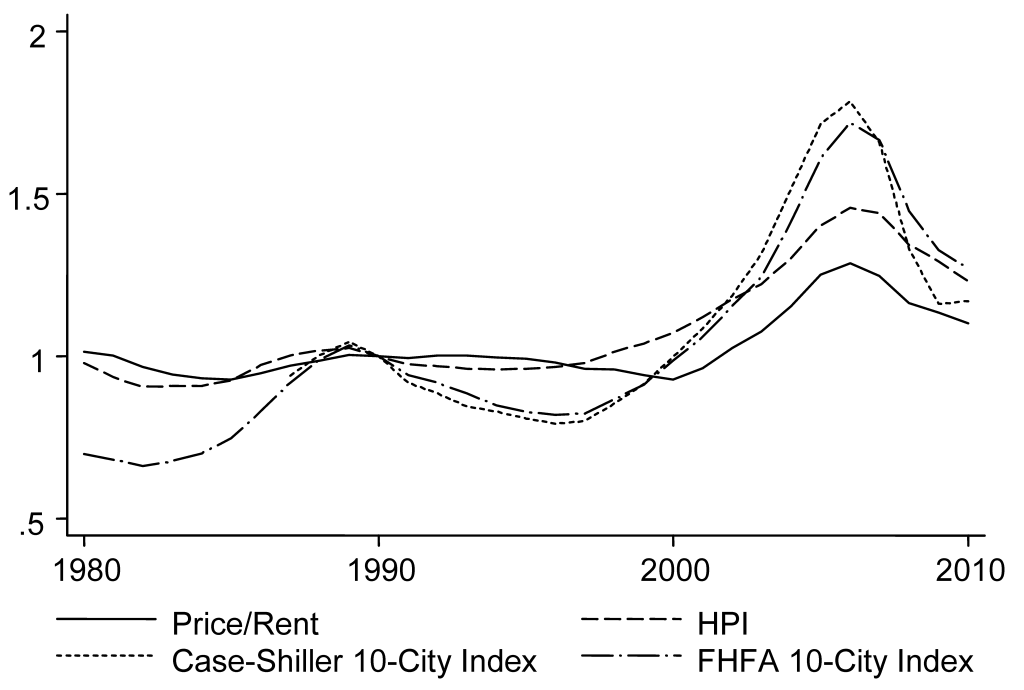

Fig. 1.1 National real house price indexes

Note: Indices are normalized to their 1990 price.

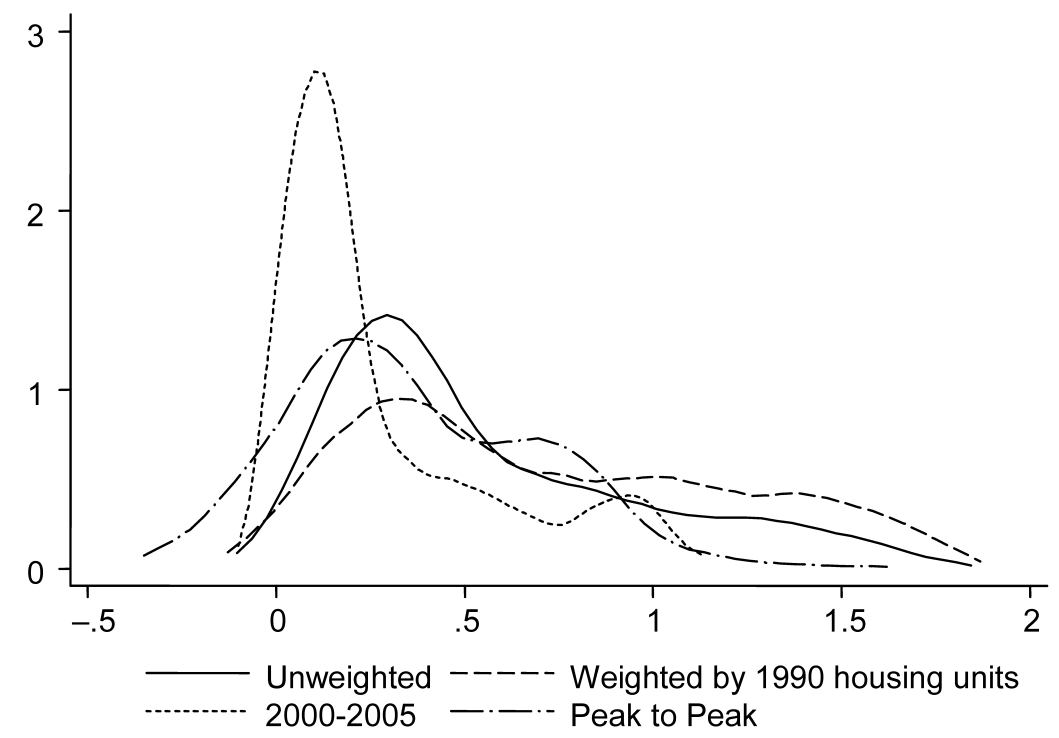

Fig. 1.2 Distribution of 1990 s and 2000 s trough-to-peak cumulative real house price growth

Source: Data comes from FHFA, deflated by the CPI.

Notes: Figure plots the distribution of MSA cumulative real house price growth between (a) the house price trough of (typically) the 1990s and the house price peak of (typically) the mid-2000s; (b) 2000 and 2005; (c) the house price peak of the late 1980s and early 1990s and the peak of the mid-2000s. 
total real price growth for the entire set of MSAs available in the FHFA data, weighting each MSA equally. Most MSAs, 57 percent, experienced real house price growth below the national average growth of 55 percent. Indeed, the mode of the distribution is below 50 percent. However, the right tail of the price growth distribution is skewed, with a number of MSAs experiencing a doubling or more in their real house prices over the period.

The skewness across MSAs in trough-to-peak real house price growth is accentuated when the MSA observations are weighted by their 1990 population of households. This result can be seen in the dashed line in figure 1.2. The peak of the distribution is reduced, with the mass redistributed to the right. This change implies that the highest trough-to-peak house price growth in the 1990s and 2000s was experienced by larger cities, so weighting by the number of households reduces the emphasis at the low-growth portion of the distribution and shifts out the right tail of the distribution.

Most of the skewness in house price growth in the 1990s and 2000s arises from exceeding the prior house price peak of the 1980s and 1990s rather than from recovering to the prior high-price-level after the trough of the 1990s. Evidence can be found in the dashed-dotted line, which is a kernel density estimate of the real house price growth between the real house price peak in the 2000s and the prior peak in house prices, which typically occurred in the late 1980s. That distribution, which is unweighted, looks very similar to the unweighted distribution of trough-to-peak real house price growth, but shifted a bit to the left.

Finally, the heterogeneity in trough-to-peak growth is not due to differences in the length of the boom. Even over a fixed time span there is considerable heterogeneity and skewness in real house price growth. This fact can be seen in the dotted line, which corresponds to house price growth over the fixed 2000 through 2005 period, rather than over the trough-to-peak period window that can vary in length. Although the mass of low-growth MSAs is greater under this fixed-time period measure, there is still considerable skewness. This pattern indicates that house prices in some MSAs grew at a higher average rate, not just for a longer period. Another potential fixed-duration measure of growth would be to compute house price growth over the five years subsequent to each MSA's trough of the 1990s, rather than using 2000 as a base year for all MSAs. The distribution generated by that approach looks very similar to the 2000 to 2005 distribution plotted in figure 1.2.

That the skewness in the distribution of MSA house price growth during the 1990s and 2000s boom is not due to differences in the length of the boom is especially evident in figure 1.3, which plots the kernel density estimate of the geometric average trough-to-peak growth rate. Most of the MSAs averaged between 0 and 5 percent real house price growth during their run-ups. However, there is a sizable tail of MSAs with annualized house price growth rates ranging between 5 and 15 percent. That tail is larger when we weight 


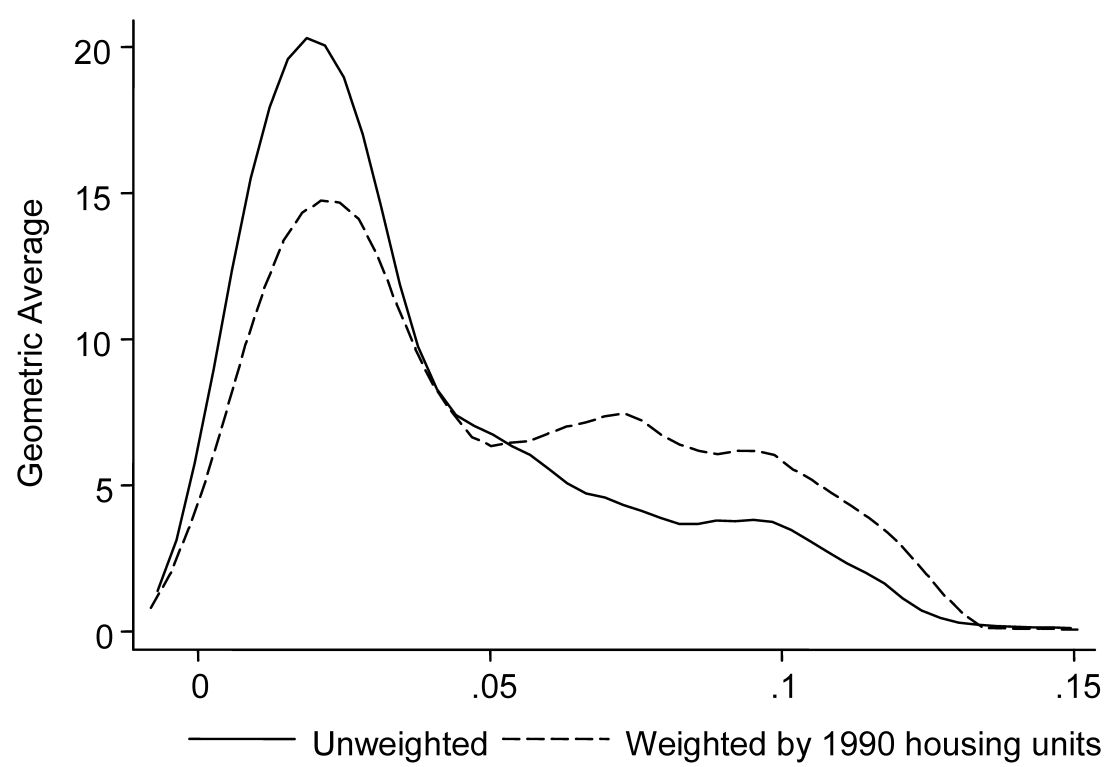

Fig. 1.3 Distribution of 1990 s and 2000s trough-to-peak average real house price growth

Source: Data comes from FHFA, deflated by the CPI.

Notes: Figure plots the distribution of MSA average real house price growth between the house price trough of (typically) the 1990s and the house price peak of (typically) the mid2000s.

by each MSA's population of housing units, depicted by the dashed line, indicating that larger cities experienced higher average house price growth rates during the most recent boom.

A similar degree of heterogeneity across MSAs can be observed in the house price declines from the peak of the 2000s through 2010, graphed in the solid line in figure 1.4. In this chart, a larger positive number corresponds to a greater decline in real house prices after the peak in the mid-2000s. Most MSAs experienced price declines, as measured by the FHFA data, of well less than the 17 percent national average. The modal decline in house prices is less than 10 percent. However, many MSAs experienced 30, 40, or even 50 percent price declines. While these MSAs are atypical, they nonetheless constitute a sizable tail. However, it is worth emphasizing that while the sample period ends in 2010, the housing collapse did not. The data do not yet allow us to compute a complete peak-to-trough measure. ${ }^{6}$

6. Just as there are a host of possible explanations for the run-up in house prices, there are many possible contributors to the bust. One potentially exacerbating factor is foreclosures, discussed in Campbell, Giglio, and Pathak (2011). 


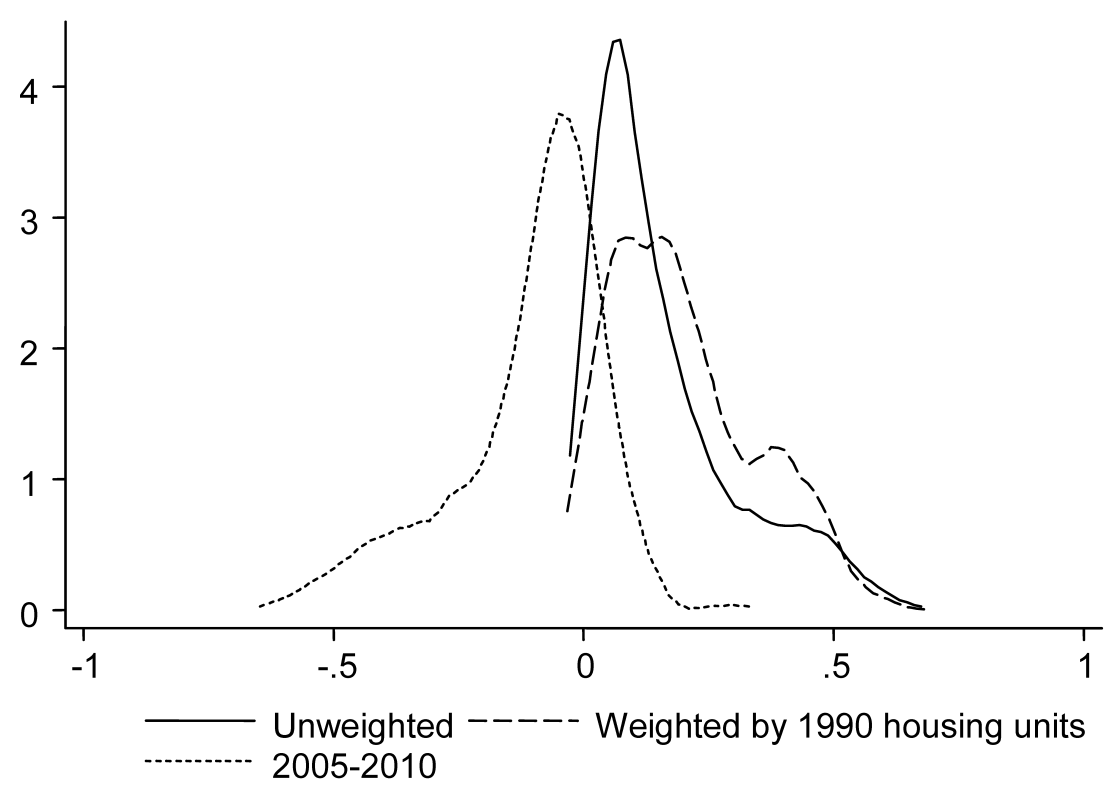

Fig. 1.4 Distribution of 2000s peak-to-trough cumulative real house price declines Source: Data comes from FHFA, deflated by the CPI.

Notes: Figure plots the distribution of MSA cumulative real house price growth between (a) the house price peak of (typically) the mid-2000s and the subsequent house price trough, often 2010, and (b) 2005 and 2010.

Even within the truncated time period, the most populous MSAs, on average, experienced larger real house price declines after their peaks. This can be seen in the dashed line, which weights each MSA observation by its number of households. The density is shifted to the right.

The dotted line in figure 1.4 graphs the distribution of house price declines between 2005 and 2010 for comparison to the 2000 to 2005 distribution in figure 1.2. A positive number indicates that house prices fell between 2005 and 2010. Some MSAs had negative declines-which correspond to increases in house prices between 2005 and 2010 - because house prices in most MSAs peaked between 2006 and 2008 and so 2005 to 2010 spans a period of price growth and subsequent decline. In many MSAs, the growth in prices between 2005 and the peak was greater than the decline from the peak to 2010, which yields a point to the left of zero. Still other MSAs had a larger house price collapse than run-up.

It is typically the case that those MSAs that experienced the greatest run-up in house prices in the 1990s and 2000s also faced the largest subsequent house price declines, even recognizing that house prices still might 
continue to decline after $2010{ }^{7}$ This pattern can be seen in figure 1.5 , which plots for 249 of the MSAs in the FHFA data the decline in log real house prices after the peak of the 2000s on the vertical axis, and the growth in log real house prices from the 1990s trough to the 2000s peak on the horizontal axis. The dashed line is the fitted bivariate regression line where each MSA is weighted equally. The upward slope (0.641 with a standard error of 0.034$)$ indicates that the magnitudes of the price run-ups and run-downs are correlated. The dotted line weights the MSAs by the population of housing units and yields a slightly lower slope $(0.518$ with a standard error of 0.031$)$. This indicates that larger MSAs had busts that were less correlated with their preceding booms.

The MSAs that are furthest away from the origin in figure 1.5 experienced boom-bust cycles with the greatest amplitudes. These mainly include a number of MSAs in Florida, such as Naples with a 173 percent real price run-up, Miami (160 percent), and Fort Lauderdale (142 percent), and others in California, such as Salinas (165 percent), Santa Barbara (162 percent), Riverside/San Bernardino (158 percent), and Modesto (141 percent).

However, the decline in real house prices is not (yet) equal to the prior increase. The solid 45-degree line in figure 1.5 demarcates the decline in log house prices that would be necessary to undo all the price growth from the 1990s trough to the house price peak of the 2000s. Nearly all of the MSAs lie below this line, indicating that their real house prices at their lowest point after the peak of the 2000 s were still above where they were in the prior trough of the 1990s. This is not surprising since, in most MSAs in 2010, the economic fundamentals that contribute to housing demand had not reverted to mid-1990s levels. Even so, some MSAs that have notably been suffering from a secular economic decline have real house prices in the late 2000s that were lower than what they were in the mid-1990s. These include many rust-belt MSAs, such as Detroit, Warren, and Flint, Michigan, Fort Wayne, Indiana, and parts of Ohio. Other MSAs whose real prices fell more than they rose in the latest boom include some "bubble" MSAs, such as Las Vegas, Nevada, and Merced, California. ${ }^{8}$

The heterogeneity across MSAs in the boom-bust cycle of house prices

7. Glaeser et al. (2011) highlight a similar phenomenon over the 1980 to 1990 s time period, that US housing markets exhibit long-run mean reversion and short-run serial correlation in house price growth. They use a fixed time window rather than MSA-specific peaks and troughs, but the idea is the same. This evidence is extended in Glaeser, Gyourko, and Saiz (2008). They, too, use the same endpoint dates for all MSAs when defining booms: 1982 to 1989,1989 to 1996, and 1996 to 2006 . We also observe a correlation in house price booms and subsequent busts in the 1980s to 1990 s period. It is not graphed, but the bivariate regression coefficient is reported in table 1.1 .

8. Glaeser, Gyourko, and Saiz (2008) note that new house construction during booms could cause house prices to fall below their level in prior troughs because housing supply could increase more than demand fundamentals. 


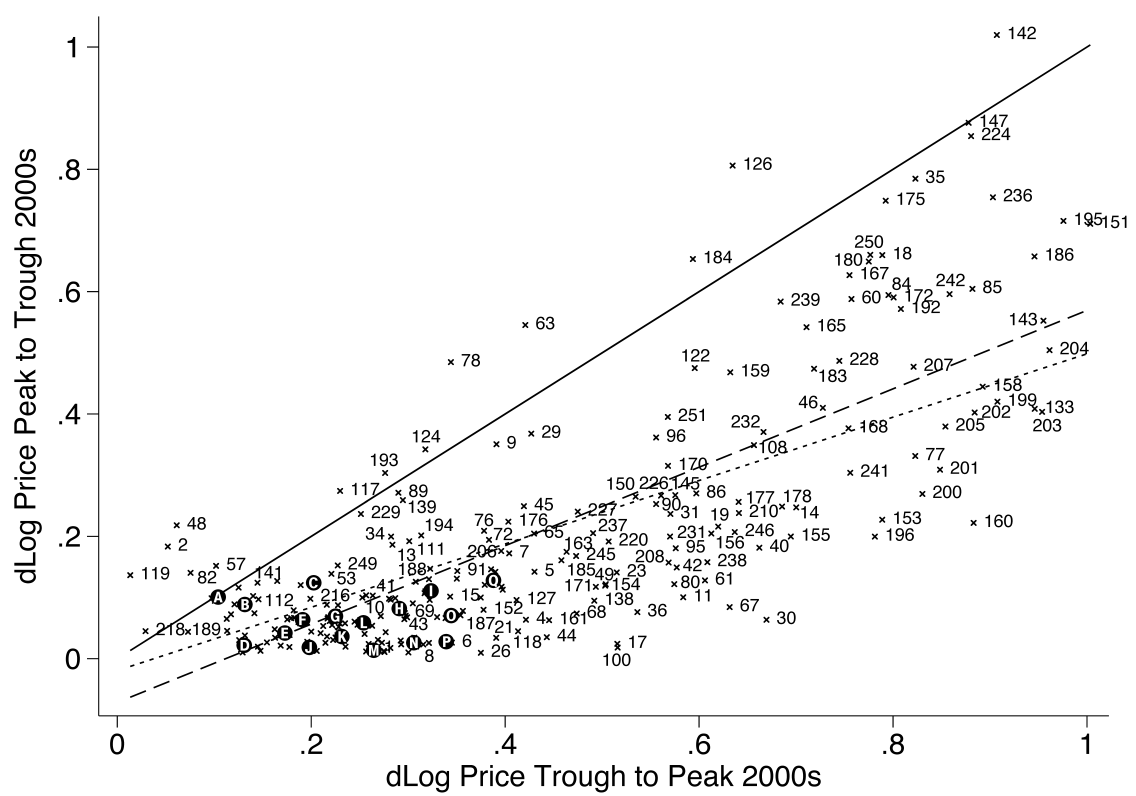

A $87,107,191$

B $92,93,104,137,140,149$

C $47,70,129,190$

D $32,33,58,59,75,83,114$

E $56,103,115,135,173,244,247$

(• $3,28,106,166,212,230$

\author{
G $16,37,51,99,110,174,219$ \\ () $52,62,105,116,123,130$ \\ ( $12,25,55,113,164,182,222,248$ \\ (1) $39,71,225,240,243$ \\ ( $22,79,81,94,120,233$ \\ C $38,50,54,64,73,97,128,131,181,209$
}

(id) $27,102,162,169,214,234$

(D) $74,101,121,132,197,198,213,223,235$

O $98,134,136,221$

P $24,66,88,148,215$

Q $109,125,146,157,179,211,217$

\section{Fig. 1.5 Real house price growth and decline, 1990s-2000s, by MSA}

Source: Data comes from FHFA, deflated by the CPI.

Notes: Figure plots the change in log MSA real house prices between the house price trough of (typically) the 1990s and the house price peak of (typically) the mid-2000s against the subsequent house price decline. The solid line demarcates the decline in log house prices that would exactly undo the prior growth in log prices. The straight lines are the fitted bivariate regression lines, the dashed one uses unweighted observations, and the dotted one uses observations weighted by 1990 housing units. Numbers in figs. 1.5, $1.6,1.9,1.10,1.19$, and 1.21 correspond to the following list:
1. Abilene, TX
2. Akron, $\mathrm{OH}$
3. Albany, GA
4. Albany-Schenectady-Troy, NY
5. Albuquerque, NM
6. Alexandria, LA
7. Allentown-Bethlehem-Easton, PA-NJ

8. Amarillo, TX

9. Ann Arbor, MI

10. Appleton, WI

11. Asheville, NC

12. Athens-Clarke County, GA

13. Atlanta-Sandy Springs-Marietta, GA

14. Atlantic City-Hammonton, $\mathrm{NJ}$

15. Auburn-Opelika, AL

16. Augusta-Richmond County, GA-SC

17. Austin-Round Rock-San Marcos, TX

18. Bakersfield-Delano, CA

19. Baltimore-Towson, MD

20. Baltimore-Towson, MD

21. Baton Rouge, LA

22. Beaumont-Port Arthur, TX

23. Bellingham, WA

24. Binghamton, NY

25. Birmingham-Hoover, AL
26. Bismarck, ND

27. Bloomington, IN

28. Bloomington-Normal, IL

29. Boise City-Nampa, ID

30. Boulder, $\mathrm{CO}$

31. Bremerton-Silverdale, WA

32. Brownsville-Harlingen, TX

33. Buffalo-Niagara Falls, NY

34. Canton-Massillon, $\mathrm{OH}$

35. Cape Coral-Fort Myers, FL

36. Casper, WY

37. Cedar Rapids, IA

38. Champaign-Urbana, IL

39. Charleston, WV

40. Charleston-North CharlestonSummerville, SC

41. Charlotte-Gastonia-Rock Hill, $\mathrm{NC}-\mathrm{SC}$

42. Charlottesville, VA

43. Chattanooga, TN-GA

44. Cheyenne, WY

45. Chicago-Joliet-Naperville, IL (MSAD)

46. Chico, CA

47. Cincinnati-Middletown, $\mathrm{OH}_{-}$ KY-IN

48. Cleveland-Elyria-Mentor, $\mathrm{OH}$

49. Colorado Springs, CO

50. Columbia, MO
51. Columbia, SC

52. Columbus, GA-AL

53. Columbus, $\mathrm{OH}$

54. Corpus Christi, TX

55. Corvallis, OR

56. Dallas-Plano-Irving, TX (MSAD)

57. Dayton, $\mathrm{OH}$

58. Decatur, AL

59. Decatur, IL

60. Deltona-Daytona Beach-

Ormond Beach, FL

61. Denver-Aurora-Broomfield, CO

62. Des Moines-West Des Moines, IA

63. Detroit-Livonia-Dearborn, $\mathrm{MI}$ (MSAD)

64. Dothan, AL

65. Dover, DE

66. Dubuque, IA

67. Duluth, MN-WI

68. Eau Claire, WI

69. El Paso, TX

70. Elkhart-Goshen, IN

71. Erie, PA

72. Eugene-Springfield, OR

73. Evansville, IN-KY

74. Fargo, ND-MN

75. Fayetteville, NC 
76. Fayetteville-Springdale-Rogers, AR-MO

77. Flagstaff, AZ-UT

78. Flint, MI

79. Florence, SC

80. Fort Collins-Loveland, $\mathrm{CO}$

81. Fort Smith, AR-OK

82. Fort Wayne, IN

83. Fort Worth-Arlington, TX (MSAD)

84. Fresno, CA

85. Ft. Lauderdale-Pompano Bch.-

Deerfield Bch., FL (MSAD)

86. Gainesville, FL

87. Gary, IN (MSAD)

88. Grand Forks, ND-MN

89. Grand Rapids-Wyoming, MI

90. Greeley, CO

91. Green Bay, WI

92. Greensboro-High Point, NC

93. Greenville, NC

94. Greenville--Mouldin-Easley, SC

95. Gulfport-Biloxi, MS

96. Hagerstown-Martinsburg, MD-WV

97. Harrisburg-Carlisle, PA

98. Hattiesburg, MS

99. Hickory-Lenoir-Morganton, $\mathrm{NC}$

100. Houma-Bayou Cane-

Thibodaux, LA

101. Houston-Sugar Land-Baytown, TX

102. Huntington-Ashland, WV-

$\mathrm{KY}-\mathrm{OH}$

103. Huntsville, AL

104. Indianapolis-Carmel, IN

105. Iowa City, IA

106. Jackson, MS

107. Jackson, TN

108. Jacksonville, FL

109. Janesville, WI

110. Joplin, MO

111. Kalamazoo-Portage, MI

112. Kankakee-Bradley, IL

113. Kansas City, MO-KS

114. Kennewick-Pasco-Richland, WA

115. Killeen-Temple-Fort Hood, TX

116. Knoxville, TN

117. Kokomo, IN

118. La Crosse, WI-MN

119. Lafayette, IN

120. Lafayette, LA

121. Lake Charles, LA

122. Lakeland-Winter Haven, FL

123. Lancaster, PA

124. Lansing-East Lansing, MI

125. Las Cruces, NM

126. Las Vegas-Paradise, NV

127. Lawrence, KS

128. Lexington-Fayette, KY

129. Lima, OH

130. Lincoln, NE

131. Little Rock-North Little RockConway, AR

132. Longview, TX

133. Los Angeles-Long BeachGlendale, CA (MSAD)

134. Louisville-Jefferson County, KY-IN

135. Lubbock, TX

136. Lynchburg, VA

137. Macon, GA

138. Madison, WI
139. Mansfield, $\mathrm{OH}$

140. McAllen-Edinburg-Mission, TX

141. Memphis, TN-MS-AR

142. Merced, CA

143. Miami-Miami Beach-Kendall, FL (MSAD)

144. Milwaukee-Waukesha-West Allis, WI

145. Minneapolis-St. PaulBloomington, $\mathrm{MN}-\mathrm{WI}$

146. Mobile, AL

147. Modesto, CA

148. Monroe, LA

149. Montgomery, AL

150. Myrtle Beach-North Myrtle

Beach-Conway, SC

151. Naples-Marco Island, FL

152. Nashville-Davidson-

Murfreesboro-Franklin, TN

153. Nassau-Suffolk, NY (MSAD)

154. New Orleans-Metairie-Kenner, LA

155. New York-White Plains-Wayne, NY-NJ (MSAD)

156. Newark-Union, NJ-PA (MSAD)

157. Niles-Benton Harbor, MI

158. Oakland-Fremont-Hayward, CA (MSAD)

159. Ocala, FL

160. Ocean City, NJ

161. Odessa, TX

162. Oklahoma City, OK

163. Olympia, WA

164. Omaha-Council Bluffs, NE-IA

165. Orlando-Kissimmee-Sanford,

FL

166. Owensboro, KY

167. Palm Bay-Melbourne-

Titusville, FL

168. Panama City-Lynn HavenPanama City Beach, FL

169. Parkersburg-Marietta-Vienna, WV-OH

170. Pensacola-Ferry Pass-Brent, FL

171. Philadelphia, PA (MSAD)

172. Phoenix-Mesa-Glendale, AZ

173. Pittsburgh, PA

174. Pocatello, ID

175. Port St. Lucie, FL

176. Portland-Vancouver-Hillsboro, OR-WA

177. Poughkeepsie-Newburgh-

Middletown, NY

178. Provo-Orem, UT

179. Pueblo, $\mathrm{CO}$

180. Punta Gorda, FL

181. Raleigh-Cary, NC

182. Reading, PA

183. Redding, CA

184. Reno-Sparks, NV

185. Richmond, VA

186. Riverside-San Bernardino-

Ontario, CA

187. Roanoke, VA

188. Rochester, MN

189. Rochester, NY

190. Rockford, IL

191. Rocky Mount, NC

192. Sacramento-Arden-ArcadeRoseville, CA

193. Saginaw-Saginaw Township North, MI
194. Salem, OR

195. Salinas, CA

196. Salt Lake City, UT

197. San Angelo, TX

198. San Antonio-New Braunfels, TX

199. San Diego-Carlsbad-San

Marcos, CA

200. San Francisco-San MateoRedwood City, CA (MSAD)

201. San Jose-Sunnyvale-Santa Clara, CA

202. San Luis Obispo-Paso Robles, CA

203. Santa Ana-Anaheim-Irvine, CA (MSAD)

204. Santa Barbara-Santa MariaGoleta, CA

205. Santa Cruz-Watsonville, CA

206. Santa Fe, NM

207. Santa Rosa-Petaluma, CA

208. Savannah, GA

209. Scranton-Wilkes-Barre, PA

210. Seattle-Bellevue-Everett, WA (MSAD)

211. Sheboygan, WI

212. Sherman-Denison, TX

213. Shreveport-Bossier City, LA

214. Sioux City, IA-NE-SD

215. Sioux Falls, SD

216. South Bend-Mishawaka, IN-MI

217. Spokane, WA

218. Springfield, IL

219. Springfield, MO

220. St. Cloud, $M N$

221. St. Joseph, MO-KS

222. St. Louis, MO-IL

223. State College, PA

224. Stockton, CA

225. Syracuse, NY

226. Tacoma, WA (MSAD)

227. Tallahassee, FL

228. Tampa-St. Petersburg-

Clearwater, FL

229. Toledo, $\mathrm{OH}$

230. Topeka, KS

231. Trenton-Ewing, NJ

232. Tucson, AZ

233. Tulsa, OK

234. Tyler, TX

235. Utica-Rome, NY

236. Vallejo-Fairfield, CA

237. Vineland-Millville-Bridgeton, $\mathrm{NJ}$

238. Virginia Beach-NorfolkNewport News, VA-NC

239. Visalia-Porterville, CA

240. Waco, TX

241. Washington-ArlingtonAlexandria, DC-VA-MD-WV (MSAD)

242. West Palm Beach-Boca RatonBoynton Beach, FL (MSAD)

243. Wichita Falls, TX

244. Wichita, KS

245. Wilmington, DE-MD-NJ (MSAD)

246. Wilmington, NC

247. Yakima, WA

248. York-Hanover, PA

249. Youngstown-Warren-

Boardman, $\mathrm{OH}-\mathrm{PA}$

250. Yuba City, CA

251. Yuma, AZ 


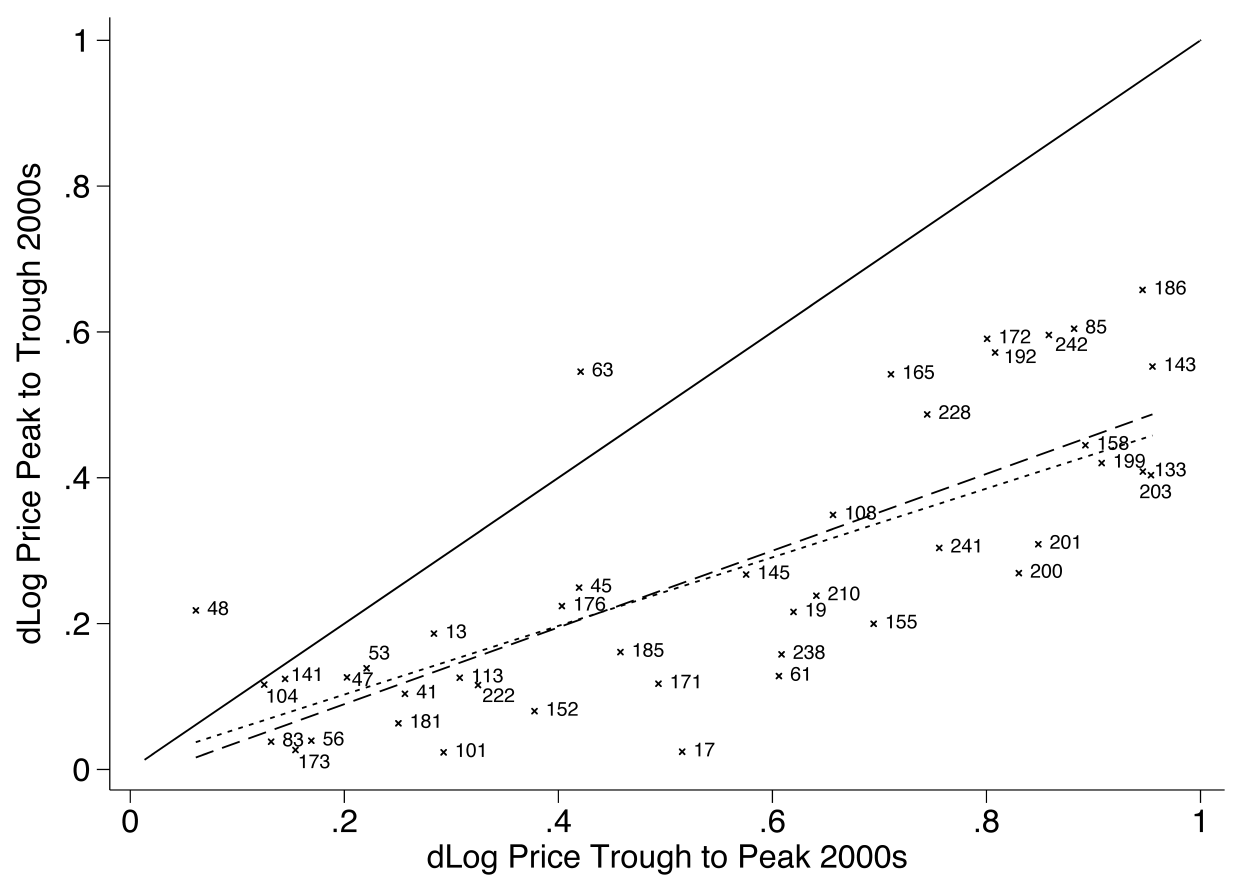

Fig. 1.6 Real house price growth and decline, 1990s-2000s, by Reis subset of MSAs

Note: See the notes to figure 1.5. This figure uses the subset of MSAs that also are in the Reis sample.

can be seen more clearly in figure 1.6, which reports the same trough-peaktrough price cycle as figure 1.5, but which restricts the sample of MSAs to those also covered by the Reis data. These forty-three MSAs are among the largest in the United States. The MSAs furthest from the origin - those with the largest price increases and decreases include most of California and South Florida, plus Phoenix, Arizona. Texas cities, such as Houston, Dallas, and Fort Worth had negligible price cycles and are close to the origin. Philadelphia, Baltimore, Seattle, New York, and Boston are in the middle. Only Cleveland and Detroit are above the 45-degree line, where their post-boom real house prices are below the level of their prior trough.

Those MSAs that are below the dashed and dotted fitted regression lines experienced a greater ratio of price increase to subsequent decrease than did the cities above the regression line. Some MSAs in close proximity experienced similar trough-to-peak price growth but dissimilar price declines. For example, as reported in appendix table 1A.1, both Los Angeles and San Bernardino/Riverside experienced 157 percent price growth between 1997 and 2006. However, prices in Los Angeles fell "just" 34 percent subsequently, compared to 48 percent in San Bernardino. In San Francisco, prices rose 129 percent from trough to peak and 124 percent in nearby Sacramento. 
But real prices have fallen by 44 percent from the peak in Sacramento and only 24 percent in San Francisco. However, it is worth repeating that none of these cities have necessarily yet reached their new price trough and so judgments about price declines should be tempered.

This heterogeneity across MSAs has important implications for the possible explanations of the housing boom and subsequent bust. In particular, the many explanations that postulate a single common national factor, such as a national change in overall credit market conditions or widespread optimism about house price growth, cannot generate different price dynamics across housing markets. To account for the heterogeneity across MSAs, a change in a national factor, such as the cost of mortgage credit, would have to interact with an MSA-specific characteristic, such as the elasticity of supply, in order to generate housing cycles of different magnitudes across MSAs. ${ }^{9}$

Another possibility is that some precipitating factor for the boom and bust might simply have varied differentially across metropolitan areas over time. For example, if subprime credit availability increased in some MSAs, as in Mian and Suf (2009), and subprime loans were capitalized into higher house prices (Pavlov and Wachter 2009), then some of the house price boom potentially could have been caused by local variation in credit supply. However, in order to be the sole explanation of the heterogeneity in the data, the growth in subprime credit would have to be largest in the MSAs with the most extreme booms, and subprime credit would have to be commensurately withdrawn during the bust. Indeed, there is evidence that the availability of subprime credit was a contributing factor to the boom. Mian and Sufi (2009) suggest that differences in credit availability could account for 40 percent of the price growth in the boom. Of course, even if differences across MSAs in the housing boom could be explained by idiosyncratic differences in subprime lending, or some other precipitating factor such as housing speculation (Bayer, Geissler, and Roberts 2011), it begs the question of why that factor would be more prevalent in particular MSAs. It could be the case that subprime lending or speculative investing happened to be located in particular MSAs for reasons that were based on exogenous characteristics. Or, perhaps, the growth in those activities was based on features of or expectations about the local housing market. In either case, lending or speculation may be a symptom rather than the true underlying cause. Burnside, Eichenbaum, and Rebelo (2011) propose a model of fads to explain this sort of housing market heterogeneity that appears to be unrelated to any observable underlying factor.

\subsection{Similarity with the $1980 \mathrm{~s}$}

The same MSA-level heterogeneity in house price growth rates that characterized the boom-bust cycle that peaked in the 2000s also was present

9. Examples of this approach include Himmelberg, Mayer, and Sinai (2005) for interest rates and Brunnermeier and Julliard (2008) for money illusion. 


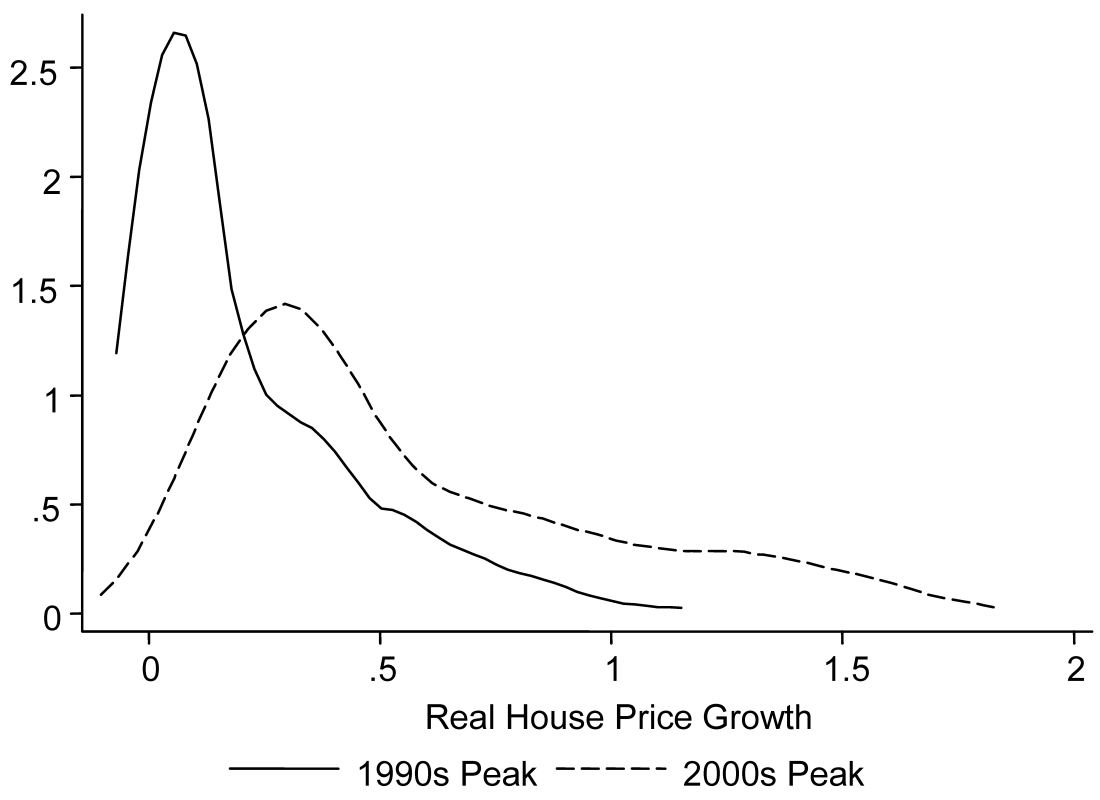

Fig. 1.7 Distribution of 1980s-1990s trough-to-peak cumulative real house price growth

Source: Data comes from FHFA, deflated by the CPI.

Note: Figure plots the distribution of MSA cumulative real house price growth between the house price trough of (typically) the 1980s and the house price peak of (typically) the late 1980 s to early 1990 s.

in the preceding house price cycle that peaked in the late 1980s. Figure 1.7 compares the unweighted distribution of real house price growth rates from the 1990 s trough to the 2000 s peak, as computed in figure 1.2, to the distribution of real house price growth rates from the 1980s trough to the peak of the late 1980s and early 1990s. Both boom-bust cycles demonstrated considerable dispersion across MSAs in trough-to-peak house price growth. A large fraction of the distribution of MSA house price growth during the 1990s boom, which is described by the solid line, is below 25 percent. However, the tail extends to growth of more than 100 percent. The dashed line, which corresponds to the boom that peaked in the 2000s, shows that the mass of the distribution of price growth in that run-up was shifted slightly more to the right than in the prior boom, up to about 50 percent increases in real house prices. The 2000 boom also had a thicker right tail, extending to more than 150 percent cumulative growth.

Both periods also exhibited dispersion in house price declines after their respective peaks. In figure 1.8, the kernel density of the decline in real house prices after the peak of the late 1980s (the solid line) is nearly the same as the density of real house price declines after the peak of the late 2000s (the 


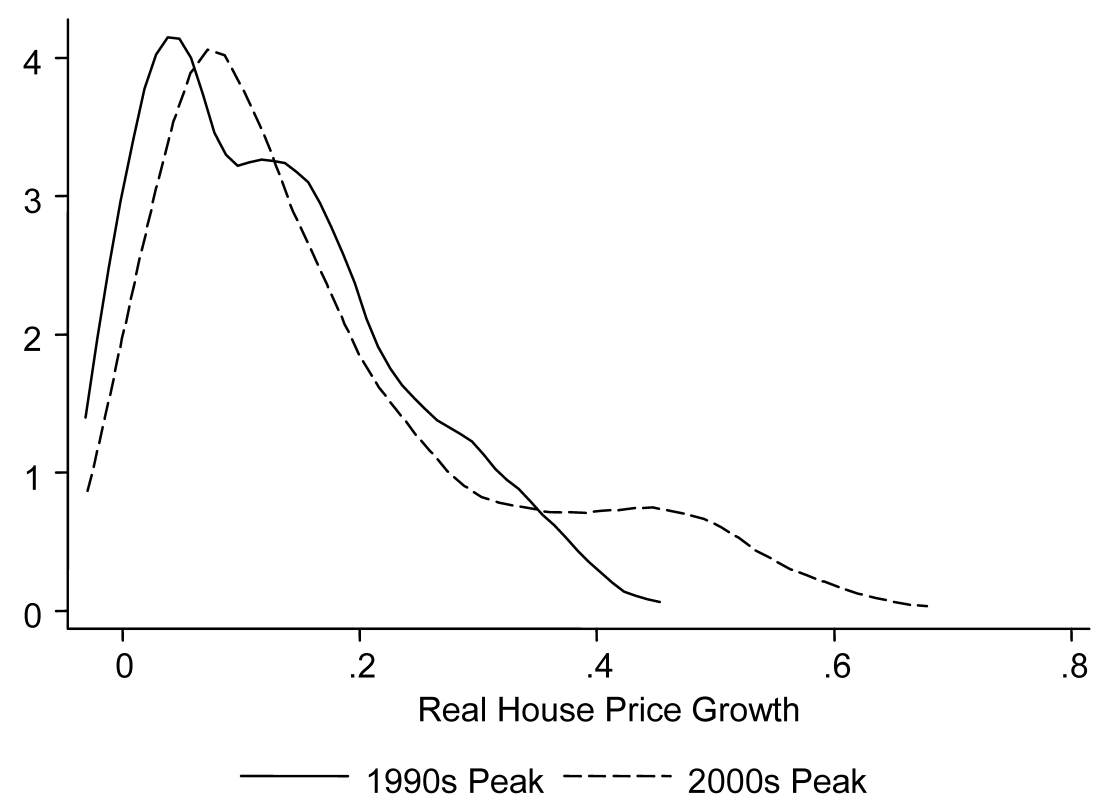

Fig. 1.8 Distribution of 1990s-2000s peak-to-trough cumulative real house price declines

Source: Data comes from FHFA, deflated by the CPI.

Note: Figure plots the distribution of MSA cumulative real house price declines between the house price peak of (typically) the late 1980s to early 1990s and the house price trough of (typically) the mid-1990s.

dashed line). The more recent housing bust reveals a somewhat larger house price collapse across most MSAs as the distribution of house price declines is shifted to the right. On top of that, the extent of the house price declines in the most recent bust is not yet fully known, whereas the 1990s bust is complete. That suggests that the most recent bust promises to be even more sizable than the house price collapse of the 1990s.

In addition, the MSAs that boomed in the 2000s largely were the same MSAs that boomed in the 1980s, with a few notable exceptions. This relationship can be seen in figure 1.9, which plots each MSA's trough-to-peak change in log real house prices during the cycle that peaked in the 2000s against trough-to-peak log house price changes during the 1980s cycle. Every MSA that had a 1980s cycle - even if it was small-is included in the sample, yielding 124 MSAs. On average, there is a positive relationship between house price growth in the two cycles, with higher trough-to-peak price growth in the 1980s predicting greater trough-to-peak price growth in the more recent cycle. This pattern can be seen in the dashed and dotted lines, which correspond to the unweighted and population-weighted bivariate regression lines, respectively. The MSAs that experienced considerable 


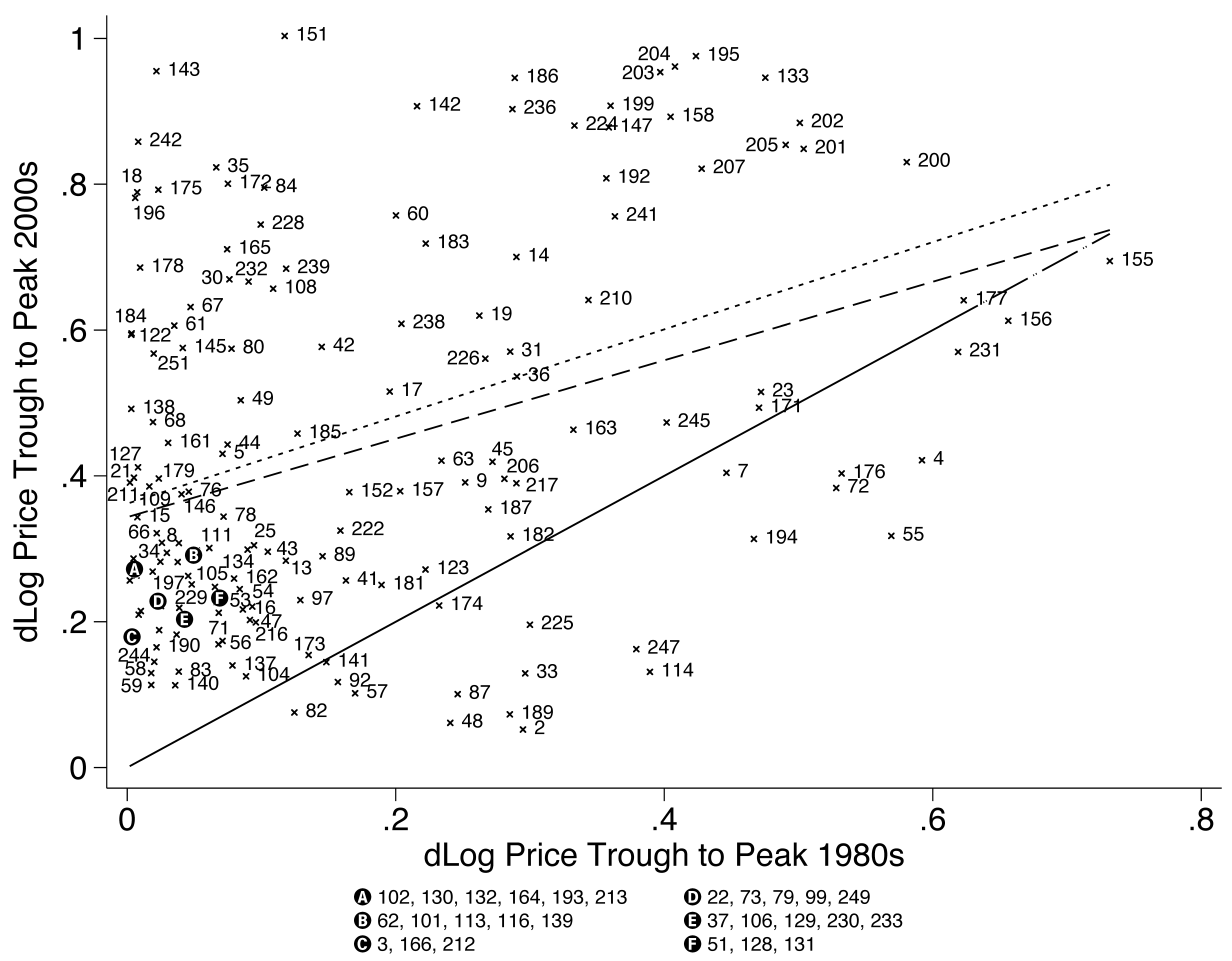

Fig. 1.9 Real house price growth, 1980s-1990s versus 1990s-2000s, by MSA

Source: Data comes from FHFA, deflated by the CPI.

Notes: Figure plots the cumulative change in MSA log real house prices between the house price trough of (typically) the 1990s and the house price peak of (typically) the mid-2000s against the trough-to-peak change in log house prices in the boom of the 1990s. The solid 45-degree line demarcates the log point increase in 2000s prices that would exactly equal the increase in 1980s prices. The straight lines are the fitted bivariate regression lines, the dashed one uses unweighted observations, and the dotted one uses observations weighted by 1990 housing units.

volatility in the 2000s, such as Boston, New York, and San Francisco, also had large house price run-ups in the 1980s, and thus can be found away from the origin on the right side of the chart. Other MSAs, such as Nashville, Austin, and Minneapolis, had relatively low amounts of house price growth in both cycles and are close to the origin. Nearly all cities, however, experienced more house price growth in the 2000s cycle than in the 1990s and thus are above the solid 45-degree line. Rather, those that experienced above-average high price growth in the 1980s typically also had above-average house price growth in the 2000s. An exception to this rule is the group of declining MSAs, such as Rochester, New York, Fort Wayne, Indiana, and Dayton, Ohio, which had little house price growth in both the 1980s and the 2000s.

There is one significant group of outliers to this general pattern. A cohort of MSAs experienced outsized house price growth in the 2000s but rela- 


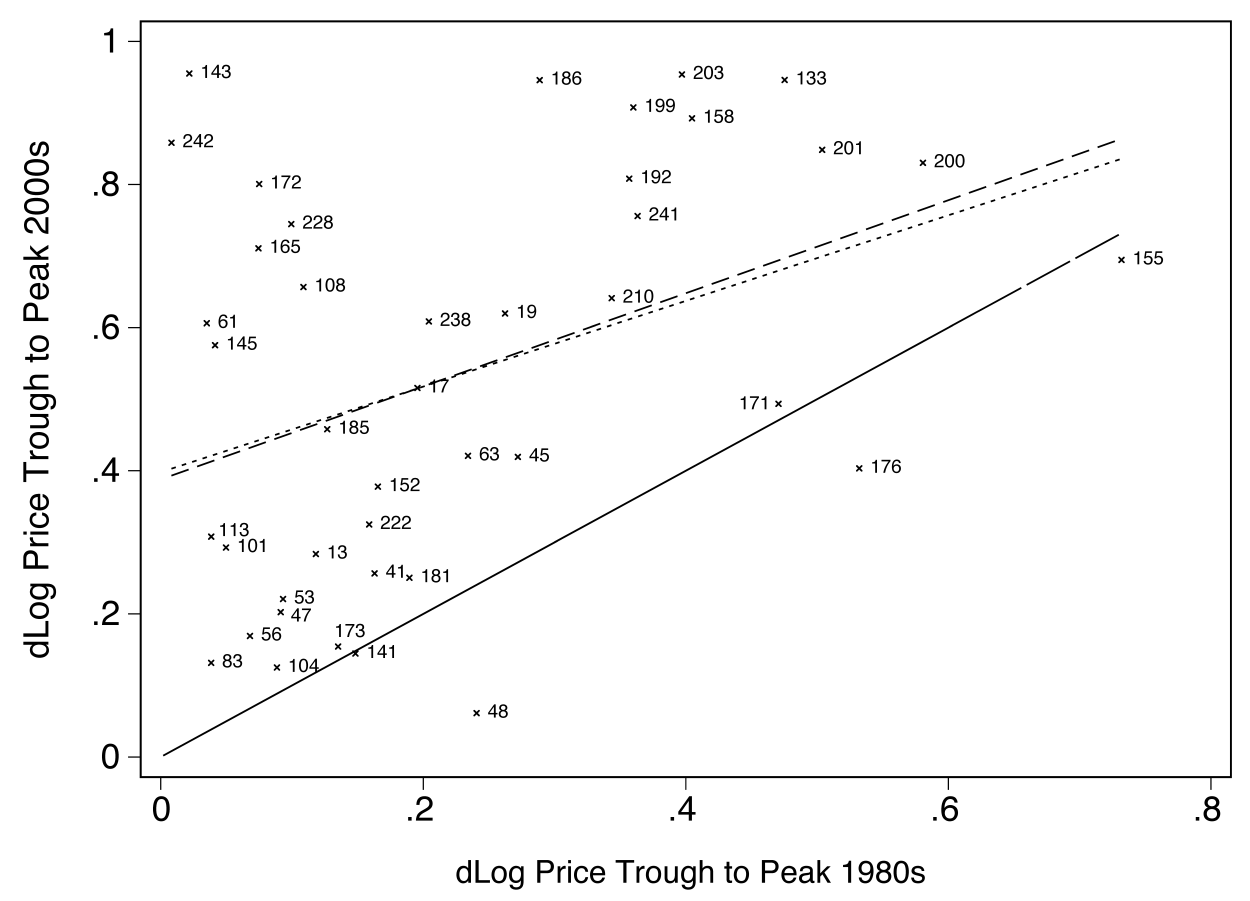

Fig. 1.10 Real house price growth, 1980s-1990s versus 1990s-2000s, by Reis subset of MSAs

Note: See the notes to figure 1.9. This figure uses the subset of MSAs that also are in the Reis sample.

tively little price growth in the 1980s. This set of MSAs is located in the upper left of the graph, close to the Y-axis and far from the X-axis. This group includes many MSAs that were poster children for the recent housing bubble-Miami and much of South Florida, Phoenix, Arizona, Las Vegas, Nevada, and Riverside/San Bernardino, California - as well as others that were less visible, such as Salt Lake City.

For legibility, figure 1.10 graphs the same information for the smaller sample of MSAs that also have data available from Reis. The outliers in the upper left quadrant, such as South Florida and Phoenix, are more evident in this figure. The California MSAs of San Bernardino, Orange County, San Diego, and Oakland also lie above the regression line but, unlike the Florida MSAs, they did exhibit a cycle in the 1980s, albeit a muted one.

The parallel between the 1980s and the 2000s presents a challenge for popular theories of the housing boom. Many of the commonly raised culprits for the most recent boom were simply not factors in the 1980s. For example, the subprime lending boom was an innovation of the 2000s. Thus, while Mian and Sufi (2009) attribute 40 percent of the 2002 to 2005 increase in house prices to the growth of subprime lending, it could not also have 
caused the house price cycle two decades earlier. It seems more likely that some recurring cause induced both housing booms than that two different factors separated by more than two decades caused matching housing booms across MSAs. The similarities between the 1980s and the 2000s also are hard for the Burnside, Eichenbaum, and Rebelo (2011) theory of fads to explain. It is hard to believe that fads randomly happened to recur, with similar degrees of intensity, in the same US housing markets. By contrast, the European data in Burnside, Eichenbaum, and Rebelo does not exhibit the same repeated housing cycles as the US data, making their theory more appropriate for that context.

Another challenge raised in this section is how to explain the aberrant MSAs. While most MSAs have regular housing booms and busts of varying magnitudes, others such as Phoenix, Las Vegas, the Inland Empire of California, and much of South Florida clearly experienced an unusual event in the boom of the 2000s. A key task for an explanation of the housing boom is to distinguish these MSAs that underwent an unusual event from the remainder. Did something different take place in the handful of MSAs that experienced house price swings only in the 2000s?

\subsection{Heterogeneity in Timing}

Popular discussion tends to refer to the start and end of the housing "bubble" as if there were a particular point in time in which price growth began in all MSAs and another date at which the bubble ended. In practice, those dates varied widely across MSAs. Figure 1.11 charts the distribution of trough and peak dates for the house price peak of the 1980s (in white), the trough of the 1990s (in black), and the peak of the 2000s (cross-hatched). (Appendix table 1A.1 reports these dates for each MSA in the data.) Each distribution spans a number of years. For most MSAs, the 1980s peak in real house prices occurred between 1986 and 1990. However, some MSAs peaked in the early 1980s and others peaked well into the 1990s. The early dates typically correspond to MSAs whose house prices peaked in the early 1980s, declined through the early-1990s, and then rose until the mid-2000s. For example, Denver's real house price peaked in 1983, reached a trough in 1991 , and peaked again in 2005. The MSAs with the latest peaks typically did not experience a 1980s cycle at all. Rather, their house prices fell until the late 1980s, then rose steadily until the late 2000s. However, Portland, Oregon, for example, experienced a slight house price dip after the tech boom of the late 1990s, and so the algorithm characterized that period as a local house price maximum. Leaving aside the extreme outliers in the dates of the peak, considerable heterogeneity remains over the five years spanning 1986 through 1990.

The dates of the subsequent trough in house prices are bimodal. One concentration occurs in the early 1990s, between 1990 and 1993, with a large number of MSAs hitting their troughs in 1991. The other concentration 


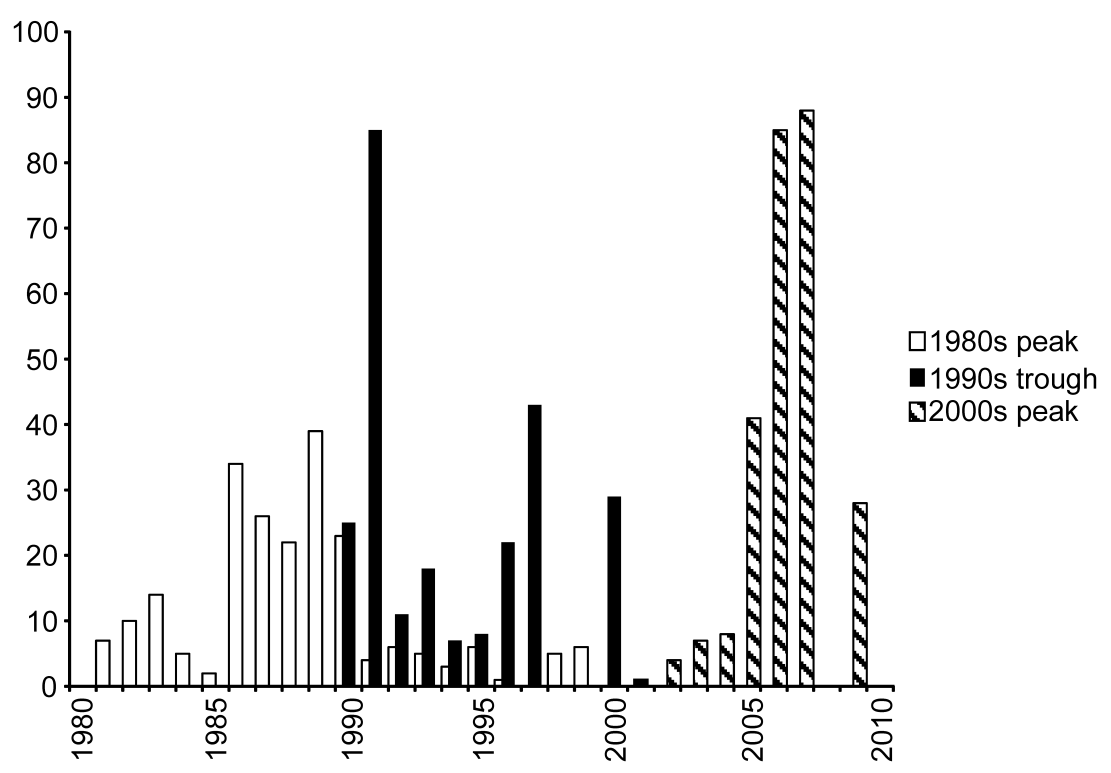

Fig. 1.11 Peak and trough years for real house prices

Note: Figure plots the histogram of peak and trough years for real house price cycles. See section 1.1 for details on the data construction.

takes place around 1996 and 1997. About thirty MSAs have troughs in 2000 or 2001. These MSAs typically experienced a small dip in house prices after a run-up in the late 1990s, before their house prices continued their climb through the late 2000s. The algorithm counts the small hiccup in house price growth as a local minimum and identifies it as a trough even if, like in Scranton, Pennsylvania, house prices reach a nadir again in the mid-1990s. Again, leaving aside the outliers, there is considerable dispersion across dates of the trough of house prices. ${ }^{10}$

By contrast, the peak of house prices in the 2000s was much more concentrated than either the previous trough or peak. The MSA-level house prices topped out primarily in 2006 and 2007, with about forty MSAs reaching their house price peaks in 2005. Despite this relatively high concentration, there is still considerable heterogeneity. House prices in twenty-six MSAs peaked before 2005 and a comparable number of MSAs had peaks in 2009. ${ }^{11}$

10. Independently, Ferreira and Gyourko (2011) have estimated the starting date of the boom of the 2000s at the MSA level using a quarterly MSA-level house price index of their own construction and a more rigorous econometric procedure. They also find considerable dispersion in starting dates.

11. Davidoff (2012) finds that most MSAs' house prices peak around Q2 of 2007 and, for those that do not, the difference between their house prices in Q2 of 2007 and house prices at their actual peaks is small. 
This heterogeneity in timing presents another hurdle for theories that attribute the housing boom(s) and bust(s) to a common national factor. Even if that factor interacts with MSA-level characteristics to induce different amplitudes of the housing market boom across MSAs, the timing of the start, peak, and end of the house price cycle should be similar. For example, the decline in interest rates in the 2000s applied to all MSAs in the United States. Even if those MSAs varied in their elasticities of housing supply or expectations of future house price appreciation - both of which could induce a differential effect of interest rates on house prices - to the extent house prices increased when interest rates fell, it should have occurred simultaneously across MSAs.

\subsection{Geographic Clustering}

Although MSAs differ in the timing and amplitude of their house price cycles, MSAs with similar house price cycles tend to be located near each other. This pattern is especially evident in the trough-to-peak and peakto-trough house price growth around the boom-bust of the 1990s and 2000s. Figure 1.12 maps the growth in real house prices between the 1990s trough and the 2000s peak, by MSA. Lighter-shaded MSAs had less troughto-peak house price growth and darker-shaded MSAs experienced more. The darkest-shaded MSAs, those with 70 percent or more growth in house prices, were mainly located on the west coast of the United States, the Northeast Corridor (Washington DC, Philadelphia, New York, and Boston), and in the state of Florida. Most of the rest of the United States is shaded light grey, indicating relatively lower house price growth, with the exception of the areas around Denver, Salt Lake City, and Casper, Wyoming. (House prices in the latter city more than doubled between 1989 and 2007.) Even among the dark-shaded subset of MSAs, the coastal MSAs experienced more growth in prices than did the slightly more inland MSAs. For example, central Florida had less trough-to-peak real house price growth than did coastal Florida. In addition, major cities had greater house price growth during this period than did neighboring areas. For example, the Portland, Oregon, MSA had more price growth than the areas just to its south, and the Boston area experienced more house price growth than the areas to its west.

Since the MSAs that had house price booms also tended to have house price busts, it follows that the house price declines of the late 2000s are also spatially concentrated. This pattern can be seen in figure 1.13 . The west coast of the United States, the northeast, and Florida experienced the largest concentrations of house price declines. However, the pattern within those areas is partially reversed from the prior house price run-up. The coastal MSAs and large cities experienced relatively less of a house price collapse by 2010 than did the more inland MSAs or the areas around the cities. However, house prices in those coastal MSAs still fell by more than in the MSAs in 


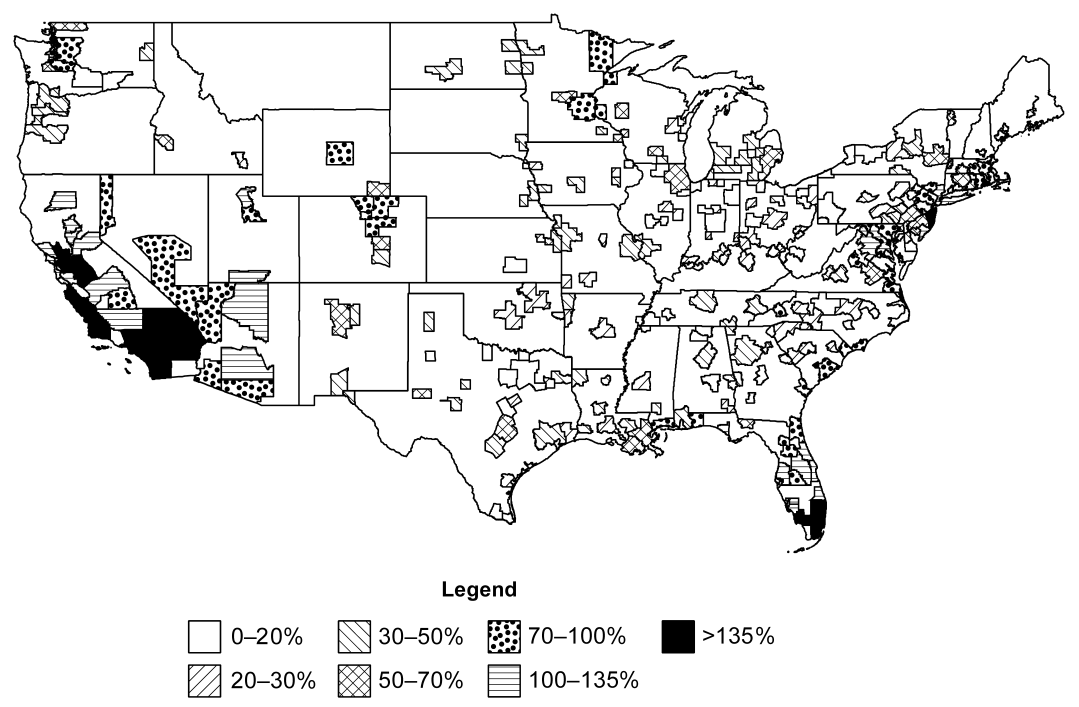

Fig. 1.12 Geography of trough-to-peak house price growth, 1990s to the 2000s Source: Data comes from FHFA, deflated by the CPI.

Note: Figure maps the MSA cumulative real house price growth between the house price trough of (typically) the 1990s and the house price peak of (typically) the mid-2000s.

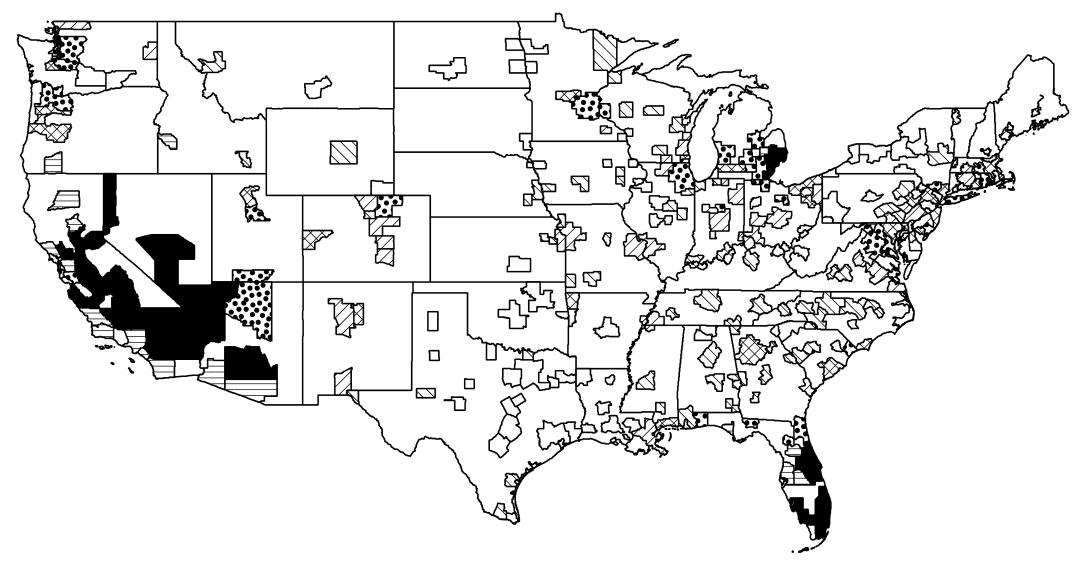

Legend

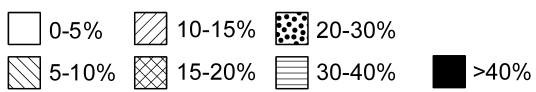

Fig. 1.13 Geography of peak-to-trough house price growth, 2000s

Source: Data comes from FHFA, deflated by the CPI.

Note: Figure maps the MSA cumulative real house price declines between the house price peak of (typically) the mid-2000s and the subsequent trough. 


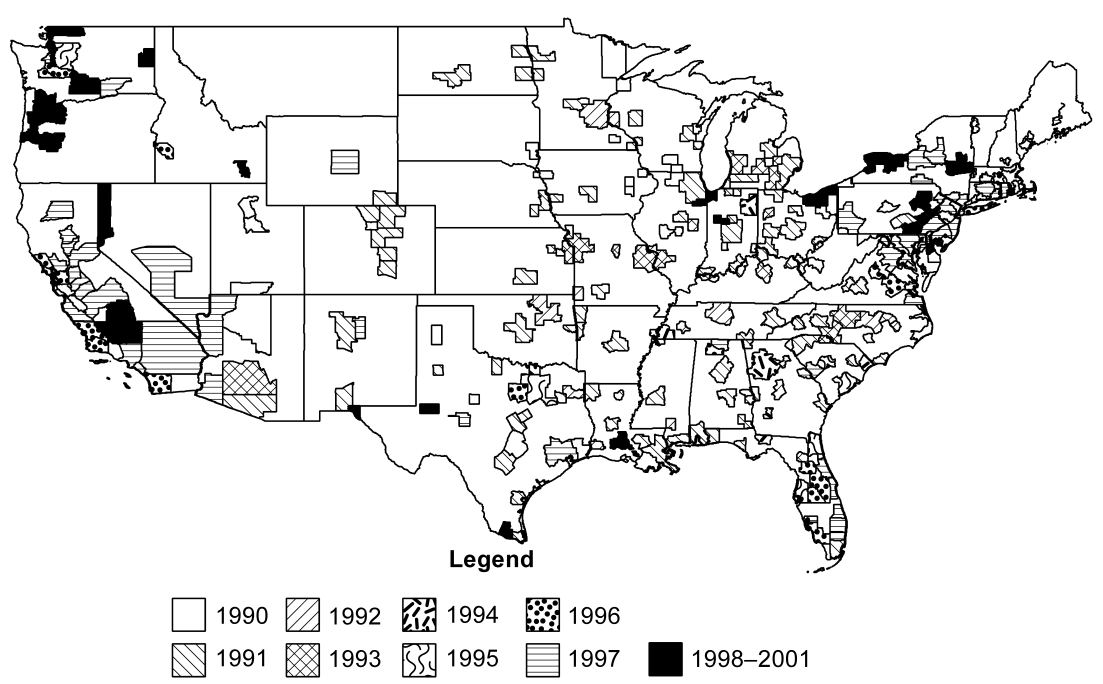

Fig. 1.14 Starting date of the 1990s and 2000s boom

Source: Data comes from FHFA, deflated by the CPI.

Note: Figure maps the date of the house price trough of (typically) the 1990s.

the middle of the country, reflecting the fact that they also experienced a greater house price rise.

Similar geographic clustering can also be seen in the starting date of the boom of the 2000s. This information is mapped in figure 1.14, with a darker shade for MSAs that had a later start date for the boom. The same areas that experienced the largest booms/busts appear to have started their cycles later. ${ }^{12}$ The estimated coefficient in a bivariate regression of the troughto-peak house price growth on the date of the trough is 0.019 ( 0.004 standard error) for 249 metropolitan areas. When the observations are weighted by the number of housing units, the estimated coefficient rises to $0.025(0.005)$.

By contrast, in figure 1.15, the dates of the peak of the 2000s house price boom are much more uniformly distributed across the country. Indeed, there is no discernible statistical correlation between the magnitude of the preceding boom and the timing of the subsequent peak in the 2000s.

This geographic clustering might provide an opportunity to uncover the source of the housing boom. It is possible that neighboring MSAs have similar observable or unobservable characteristics that made them more susceptible to house price cycles. Or, perhaps housing booms propagate — by

12. Ferreira and Gyourko (2011) independently document similar MSA-level geographic clustering in the start of the boom. Their research emphasizes the initial jump in house prices at the start of the house price boom. Interestingly, they do not find geographic clustering at the MSA level in the magnitude of those initial price jumps. 

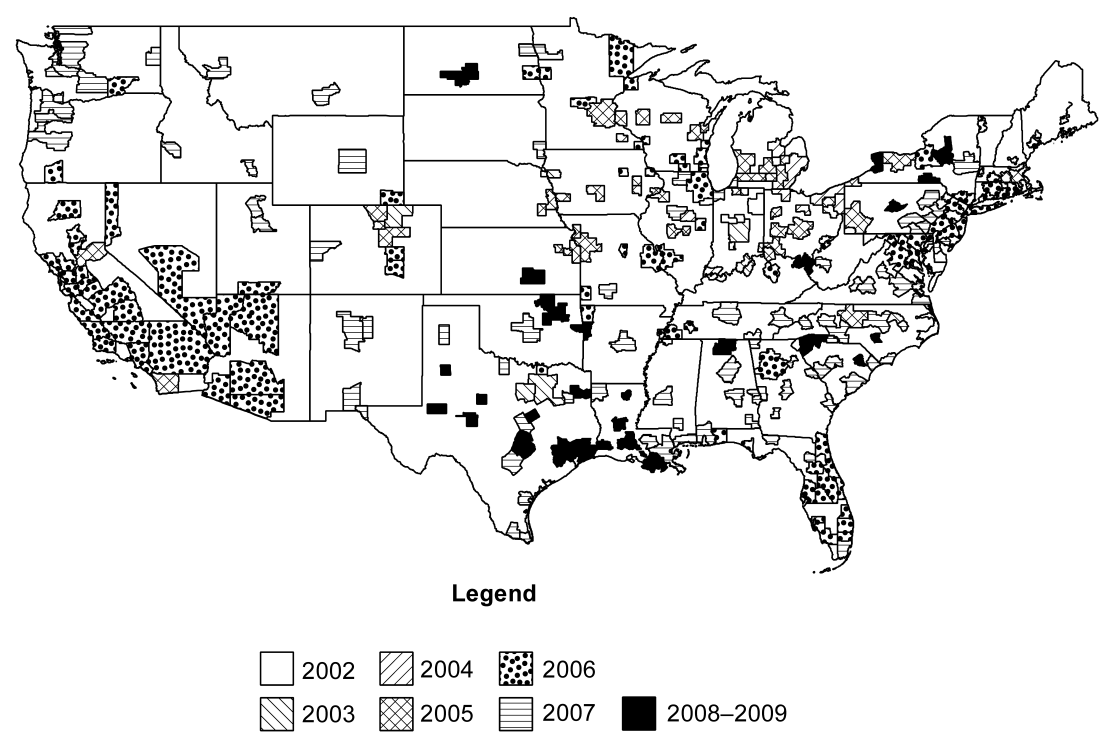

Fig. 1.15 Date of the peak of the 1990s and 2000s boom

Note: Figure maps the date of the house price peak of the mid-2000s. Data comes from FHFA, deflated by the CPI.

wealth transmission, or contagion of market information or sentimentcausing an MSA's housing market to follow its neighbor's.

\subsection{Annual House Price Growth}

Up to this point, this chapter has considered the distribution of troughto-peak and peak-to-trough growth rates. However, the distribution of annual growth rates in MSA-level house price indexes also reveals some interesting patterns.

First, the cross-sectional distribution of one-year MSA-level house price growth rates widens considerably during housing booms and contracts during housing busts. That is, when house prices are highest, there is more dispersion across MSAs in the amount of house price growth. This pattern can be seen in figure 1.16, which plots the standard deviation of real house price growth over time. The standard deviation is computed across MSAs at a point in time. For example, the line in figure 1.16 starts in 1981. That year, the standard deviation across MSAs of their house price growth between 1980 and 1981 was just under 5 percent. During the next decade, as average house prices rose, the standard deviation of house prices also grew. By 1990, the peak of the boom, that standard deviation had grown to nearly 7 percent, indicating that the variation among MSAs in the amount of house price growth was greater at the top of the cycle. In the mid-1990s, as house 


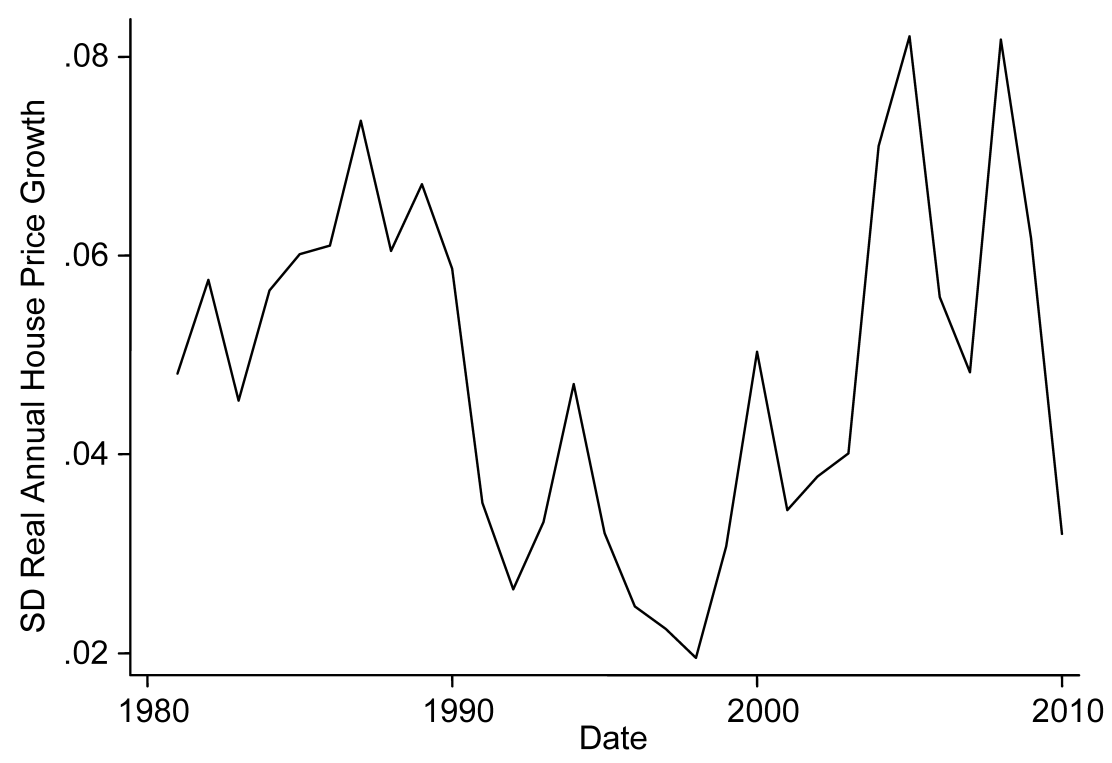

Fig. 1.16 The standard deviation of MSA-level annual real house price growth, 1981-2010

Source: Data comes from FHFA, deflated by the CPI.

Note: Figure graphs the standard deviation of annual real house price growth across MSAs in each year.

prices slumped, the cross-sectional variance also fell. But, in the boom of the 2000s, the standard deviation rose steadily with house prices to a peak of more than 8 percent.

While the standard deviation of house price growth rose in both the 1980s and the 2000s, there was one interesting difference between the two booms: In the 1980s boom, some MSAs experienced house price growth whereas others saw house prices decline. However, in the 2000s boom, almost all MSAs enjoyed house price increases. Figure 1.17 plots the distribution of annual house price growth by year. Within each year, there are 159 unweighted MSA-level observations on real house prices. The horizontal black line in the middle of each vertical black bar corresponds to the median MSA-level house price growth between the prior year and the current one. The median growth is positive between 1983 and 1989, reflecting the house price boom of that period. The cross-section dispersion increases toward the peak of the boom, in 1987, 1988, and 1989. As house prices fall through the late-1990s, the cross-sectional dispersion declines. However, during the entire 1983 to 1997 period, despite covering a significant aggregate house price boom and bust, the interquartile range (from the bottom to the top of the black bar) spanned zero. That is, some MSAs experienced real price declines in the 


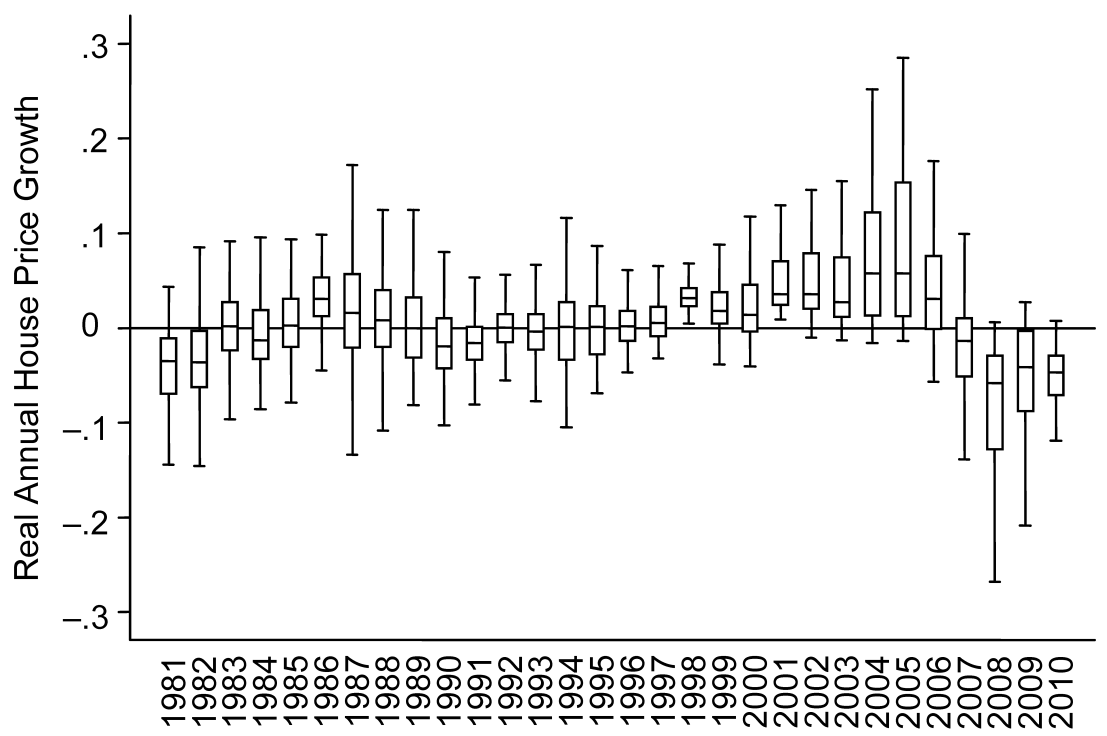

Fig. 1.17 The distribution of annual real house price growth, by year

Source: Data comes from FHFA, deflated by the CPI. Excludes outside values.

Notes: Figure plots the distribution of annual real house price growth across MSAs in each year. The black-outlined bar runs from the twenty-fifth to the seventy-fifth percentiles. The horizontal black line corresponds to the median.

same year that other MSAs experienced price growth. By 1998, that pattern was over, and during every year of the house price boom of the 2000s, with the exception of the post-Internet boom year of 2000, at least 75 percent of the MSAs (and often more) in each year experienced positive house price growth. In 2007, this was no longer true. Then, in every year between 2008 and 2010, more than 75 percent of MSAs faced house price declines. ${ }^{13}$

These patterns in annual growth rates highlight that something different was going on in the boom of the 2000s: house prices rose in all metropolitan areas, differing only by how much. But they also emphasize some important similarities across the housing booms. The increasing dispersion in annual house price growth indicates that some MSAs grew more rapidly than others, not that some just grew for a longer period of time. The cycle in dispersion also shows that there was not an equal shock to house price growth across MSAs; had there been, the entire distribution of house price growth would have shifted rather than expanding.

13. This pattern is consistent with Cotter, Gabriel, and Roll's (2011) finding of increased integration in MSA-level house prices in the 2000s. 


\subsection{House Price Cycles Remain after Controlling for Demand Fundamentals}

Up to this point, this chapter has focused on house prices alone. But, as is widely recognized, there are two components that determine house prices. The first is the fundamental value of the housing service flow, rent. The rental value of housing is determined by factors that affect the demand for living in a particular location-income, household demographics such as marital status, and local amenities or wage levels - as well as the elasticity of housing supply. The second component is an asset pricing relationship that capitalizes a stream of future rental value into a current price. ${ }^{14}$

If the rental value of owner-occupied housing could be measured directly, housing cycles could be decomposed into cycles in the value of the housing service flow and cycles due to changes in asset pricing. Of course, owneroccupied houses are by definition not rented, and thus the econometrician does not observe the rental value of that set of houses. The prior literature takes three approaches to surmount that problem. One approach is to compare the rental value and prices for a set of matched rental and owner-occupied houses, as in Smith and Smith (2006). Another strategy is to assume that the growth rate in apartment rents, which are observed, is a good proxy for the growth rate in the unobserved rental value of owneroccupied housing, as in Himmelberg, Mayer, and Sinai (2005) or Campbell et al. (2009). A third tactic is to use demand shifters, such as household income, to estimate rental value within the context of an economic model, as in Glaeser, Gottlieb, and Gyourko's chapter in this volume.

In this section, I control for various measures of the underlying rental value of owner-occupied housing in each MSA to isolate the asset pricing component. Doing this makes the cyclical pattern of house prices, if anything, stronger.

One main reason for this outcome is that, while there are cycles in fundamentals, cycles in house prices are much larger. This can be seen clearly in figure 1.18, which plots the distribution of trough-to-peak growth in the 2000 boom for four MSA-level variables: Real house prices, real rent, real income, and employment. ${ }^{15}$ House price growth, the solid line, has considerably more dispersion than any of the three measures of fundamentals. ${ }^{16}$ A sizable fraction of MSAs experienced trough-to-peak real house price growth between 50 and 200 percent. However, very few MSAs experienced

14. See, for example, Meese and Wallace (1994) for an early exposition of this present value relationship for housing. The intuition is robust to an even more complete house pricing model, such as Ortalo-Magné and Prat (2010).

15. McCarthy and Peach (2004) show that the early stages of the house price boom of the 2000s may have been due to growth in demand fundamentals.

16. Haughwout et al. (2011) shows that house price growth is correlated with growth in the price of raw land. 


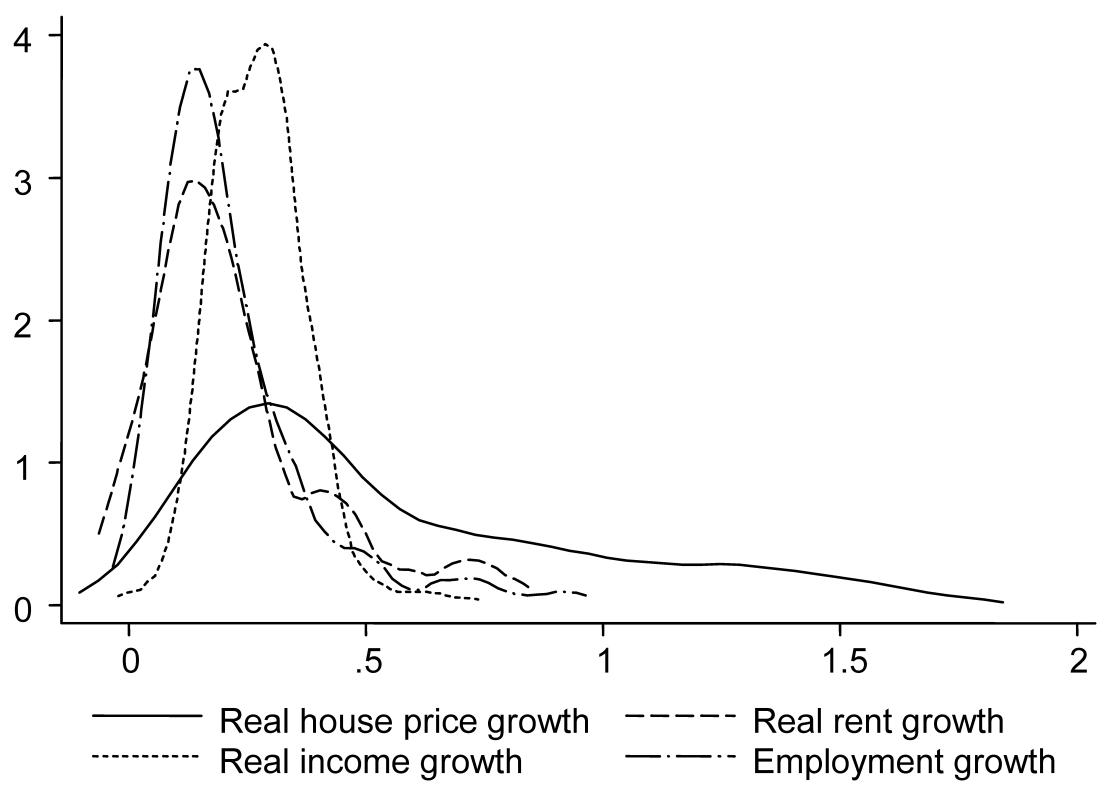

Fig. 1.18 Trough-to-peak growth in real house prices and housing demand fundamentals, 1990s-2000

Source: Data comes from FHFA, Reis, and BLS.

Note: Figure graphs the distribution of cumulative growth in real house prices, real rents, real MSA income, and MSA employment from each variable's trough in the 1990s to its peak in the 2000s.

more than 50 percent trough-to-peak growth in housing demand fundamentals, and none experienced more than 100 percent growth. ${ }^{17}$

Not only are the run-ups in fundamental values muted relative to house prices, the relationship between trough-to-peak growth and the subsequent peak-to-trough decline is attenuated. Figure 1.19 plots a cycle in real apartment rents. Each MSA's troughs and peaks in real rent are computed using the same algorithm that was applied to house prices. Then, figure 1.19 graphs the peak-to-trough change in log real apartment rents in the 2000s against the trough-to-peak log change in the 1990s and 2000s for the subset of fortythree MSAs for which we have rent data. Most MSAs experienced less than a $40 \log$ point trough-to-peak growth in rent and less than a 20 point decline from their rent peak through 2010. However, a handful of MSAs-including the San Francisco Bay area, Denver, and New York - experienced much larger rent cycles. Most MSAs lie below the solid 45-degree line, indicating

17. Figure 1.18 uses different trough and peak dates for each variable, thus the troughto-peak growth is calculated over a different sample window. However, it makes little difference in this figure if we instead compute trough-to-peak growth for each demand fundamental using the trough and peak dates for the real house price index. 


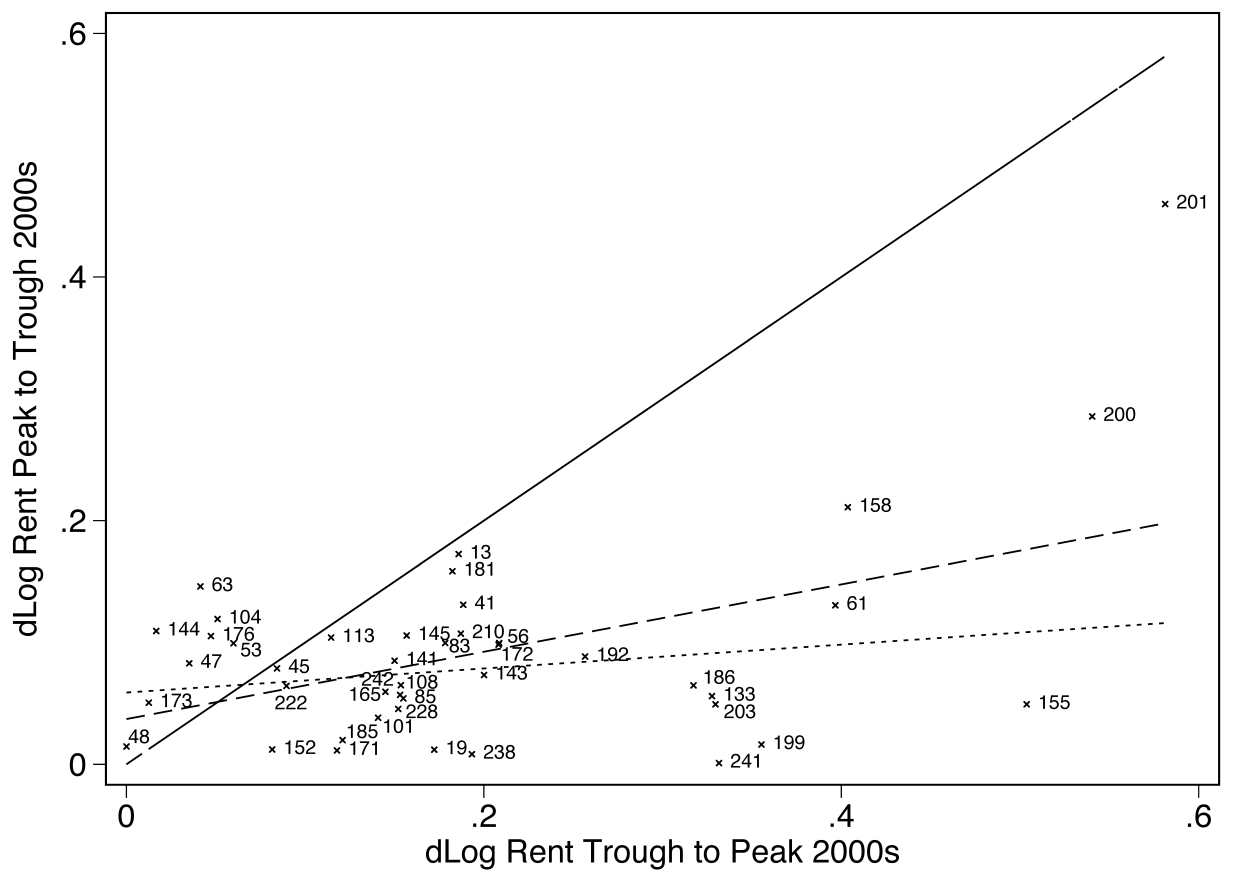

Fig. 1.19 Real rent growth and decline, 1990s-2000s, by Reis subset of MSAs Source: Data comes from Reis, deflated by the CPI.

Notes: Figure plots the MSA cumulative change in real log rents between the rent trough of (typically) the 1990s and the rent peak of (typically) the mid-2000s against the subsequent rent decline. The solid 45-degree line demarcates the log point decline in rents that would exactly undo the prior growth in rents. The straight lines are the fitted bivariate regression lines, the dashed one uses unweighted observations, and the dotted one uses observations weighted by 1990 housing units.

that rents have not fallen as much as they rose during their booms. All the exceptions are rust-belt MSAs with very little rent growth, such as Detroit, Milwaukee, and Pittsburgh. The dashed line corresponds to the unweighted bivariate regression and shows that, on average, MSAs that enjoyed more rent growth during their booms also experienced greater percentage rent declines through 2010. (The estimated coefficient on the trough-to-peak change in log real rent is 0.276 with a standard error of 0.079 .) However, when each MSA is weighted by its number of housing units, displayed in the dotted line, we do not obtain a statistically significant correlation. (The estimated coefficient is 0.098 with a standard error of 0.070 .)

In fact, all bivariate relationships discussed in this chapter are stronger for house prices than for housing demand fundamentals. This fact can be seen in table 1.1. The top panel of table 1.1 uses the subsample of MSAs for which we have rent data from Reis. Each row corresponds to a different bivariate 


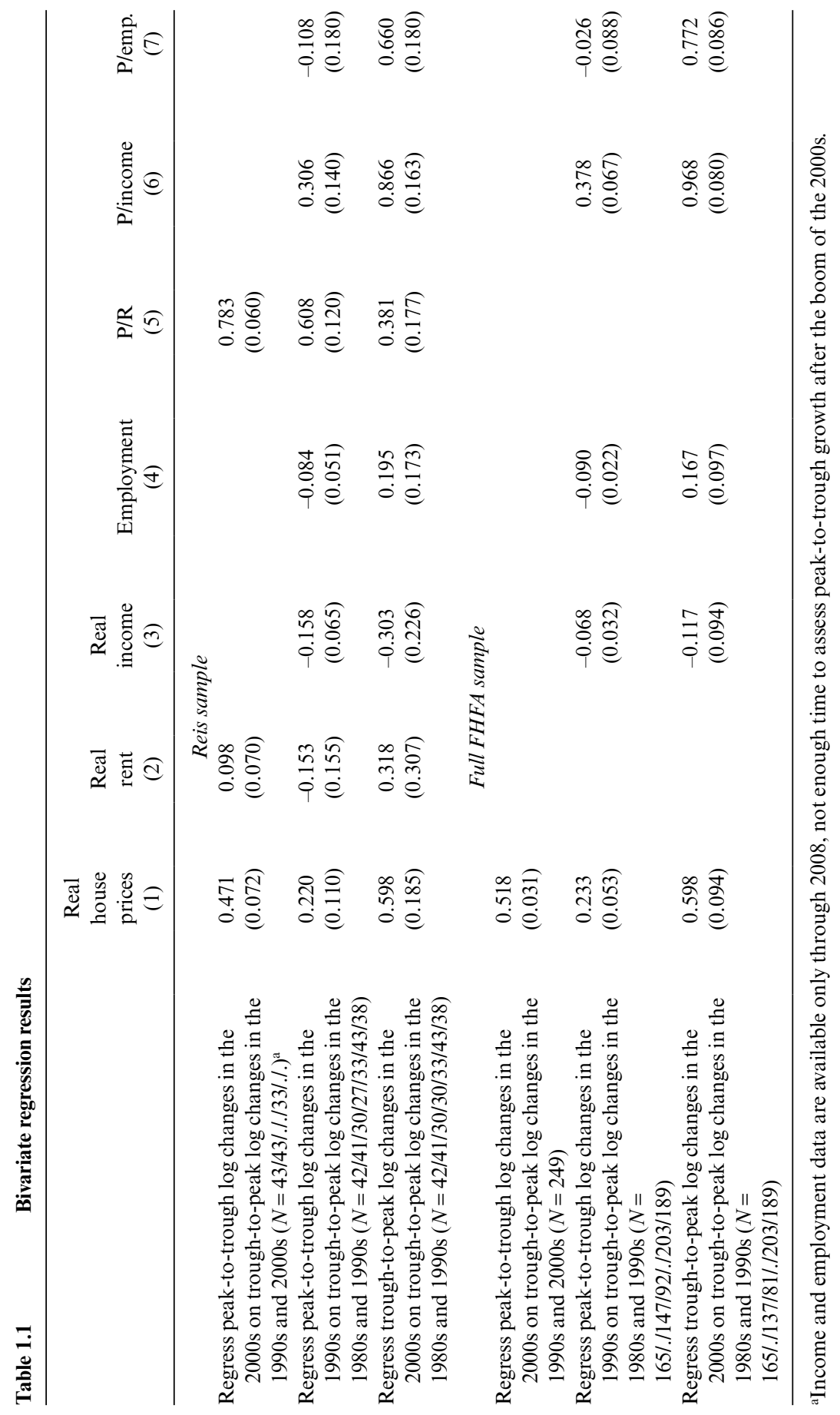


regression where the unit of observation is an MSA and each observation is weighted by the MSA's number of households. For a given variable, the first row regresses the peak-to-trough change in the log of that variable after the peak in the 2000s on the preceding trough-to-peak log change. The second row repeats the strategy for the boom/bust of the 1980s and 1990s. The third row regresses trough-to-peak log differences over the boom of the 2000s on trough-to-peak log differences over the preceding boom. The bottom panel repeats the regressions using the full FHFA sample of MSAs.

Each column of table 1.1 corresponds to a different variable of interest, and the estimated slope coefficient from the bivariate regression is reported in the cell. Cells are empty when there is not enough data for an estimate. For example, there is no rent variable in the FHFA data set, so columns (2) and (5) of the bottom panel are empty. Likewise, columns (2), (3), (6), and (7) of the top row of each panel are empty because the income and employment data do not extend far enough to allow an estimate of how much they changed after the peak of the 2000s.

In the first row and column of table 1.1, peak-to-trough real house price declines subsequent to the peak of the 2000s were $4.7 \mathrm{log}$ points larger for every additional $10 \mathrm{log}$ point increase in house price growth. (The estimated coefficient is 0.471 with a standard error of 0.072 .) The analogous coefficient from the previous boom is just half that magnitude, at $0.220(0.110)$. But house price growth is highly correlated between the two booms. The estimated coefficient of 0.598 shows that an MSA with $10 \log$ points more trough-to-peak house price growth in the 1980s and 1990s on average experienced nearly $6 \log$ points more house price growth in the 2000s boom. The bottom panel, which uses the full sample, finds similar estimated coefficients.

The second column repeats the same analyses with MSA-level real rent, the third column with real income, and the fourth column with MSA employment. In none of these columns are the estimated coefficients as large as the corresponding ones for real house prices. In addition, in most cases in the top panel they are not statistically distinguishable from zero.

Another way to see the contribution of swings in asset prices net of fundamentals to housing booms and busts is to normalize by a measure of fundamentals. Figure 1.20 plots the trough-to-peak distribution of growth between the trough of the 1990s and the peak of the 2000s in the priceto-rent, price-to-income, and price-to-employment ratios. The price-to-rent multiple should reflect the influence of factors that potentially affect housing asset pricing, such as interest rates, credit availability, expected future growth in the value of the housing service flow, adjustments for the relative riskiness of owning versus renting, and any mispricing in the housing market, while conditioning out differences across MSAs in current supply/demand fundamentals. The price-to-income and price-to-employment ratios are alternative measures that normalize by demand shifters in case rent growth for apartments does not parallel the growth in the implicit rental value of 


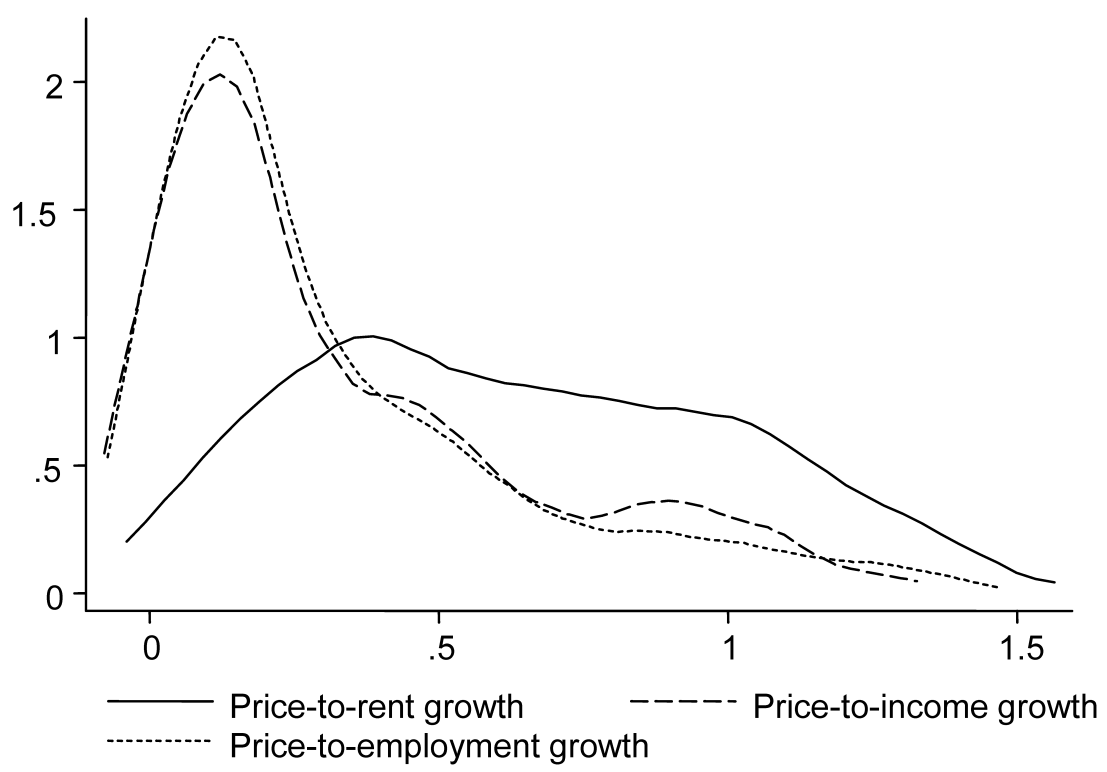

Fig. 1.20 Trough-to-peak growth in price-to-fundamentals ratios, 1990s-2000 Source: Data comes from FHFA, Reis, and BLS.

Note: Figure graphs the distribution of cumulative growth in the price-to-rent, priceto-income, and price-to-employment ratios from each variable's trough in the 1990s to its peak in the $2000 \mathrm{~s}$.

owner-occupied houses. Growth in the price-to-rent ratio exhibits nearly as much dispersion over the boom as growth in prices alone, ranging from zero to 150 percent. Growth in the price-to-income and price-to-employment ratios are more concentrated below 50 percent, but this is due to differences in the composition of MSAs that make up the full sample and the MSAs for which we have rent data. The Reis MSAs simply had more house price growth during this boom. When we plot all three series using the same subset of MSAs that are in the Reis sample, all three distributions look quite similar. The price-to-income and price-to-employment growth distributions parallel the shape of the price-to-rent distribution, but are shifted to the left by about 10 percentage points of growth.

Even though there is not much evidence of cycles in underlying demand fundamentals in this simple analysis, after controlling for the influence of fundamentals the boom-bust relationships documented in this chapter get stronger. Figure 1.21 plots the peak-to-trough decline after the 2000s peak in the log price-to-rent ratio against the trough-to-peak growth. There is a strong positive relationship - those MSAs that experienced the largest run-ups in their price-to-rent ratios also experienced the largest subsequent declines - and it is a tighter cyclical relationship than in the analogous chart 


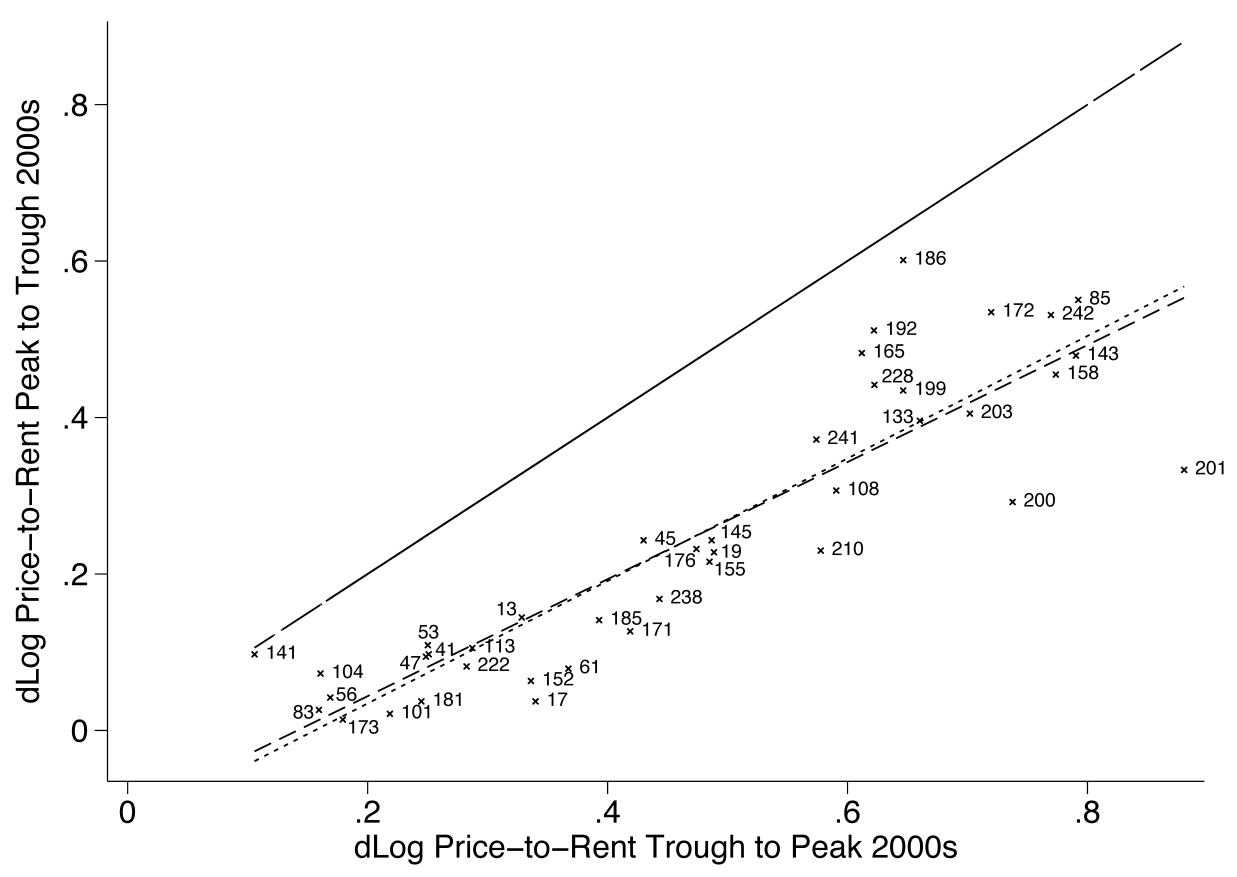

Fig. 1.21 Price-to-rent ratio growth and decline, 1990s-2000s, by Reis subset of MSAs

Source: Data comes from Reis and FHFA.

Notes: Figure plots the MSA cumulative change in the log price-to-rent ratio between the R/P trough of (typically) the 1990s and the R/P peak of (typically) the mid-2000s against the subsequent $\mathrm{R} / \mathrm{P}$ decline. The solid line demarcates the $\log$ point decline in $\mathrm{R} / \mathrm{P}$ that would exactly undo the prior growth in R/P. The straight lines are the fitted bivariate regression lines, the dashed one uses unweighted observations, and the dotted one uses observations weighted by 1990 housing units.

for house prices alone (figure 1.6, which uses the same sample of MSAs). The MSAs lie closer to the regression line-the adjusted $R$-squared that corresponds to the weighted bivariate regression line is 0.81 in figure 1.20 and just 0.53 in figure 1.6. In addition, the regression line is closer to the 45 -degree line that signifies the point where the price-to-rent ratio has reverted to its prior trough levels.

The last three columns of table 1.1 report the estimated coefficients for the set of bivariate regressions on the price-to-rent, price-to-income, and price-to-employment ratios. There is a stronger boom-bust pattern in priceto-rent ratios than in house prices alone in the booms of the 2000s and the 1980s and 1990s (the first two rows). However, the link between the run-up of the 1980s and the run-up in the 1990s and 2000s was stronger in house prices than in price-to-rent ratios. This pattern does not persist with our other two measures of fundamentals. For price/income, the boom-bust relationship is 


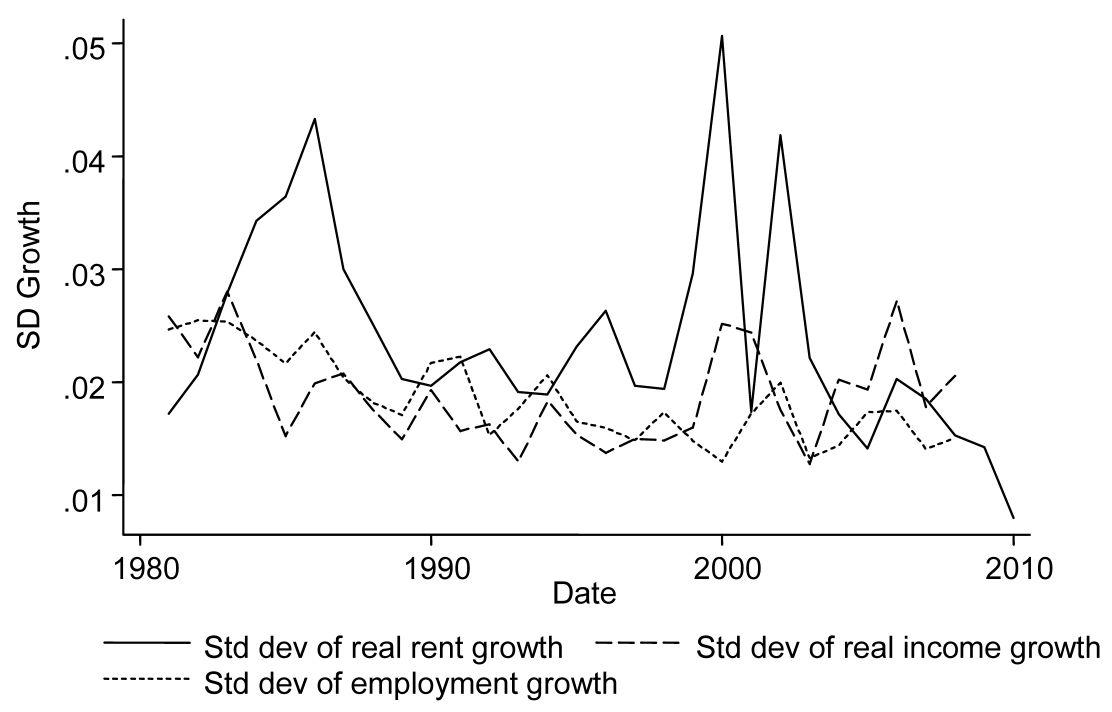

Fig. 1.22 The standard deviation of MSA-level annual growth in demand fundamentals

Source: Data comes from Reis and BLS, deflated by the CPI.

Note: Figure graphs the standard deviations of annual real rent, real income, and employment growth across MSAs in each year.

tighter during the 1980s and 1990s cycle and the 1980s booms are more correlated with the 1990s and 2000s booms. By contrast, price-to-employment does not exhibit much of any boom/bust cycle in the 1980s, but MSAs with high growth in price-to-employment in the 1990s and 2000s were also likely to experience high growth in the same ratio in the 1980s boom.

Turning back to annual growth rates, the growth in housing demand fundamentals does not show the same increases in cross-sectional dispersion during booms as we saw in house prices. Figure 1.22 plots the standard deviation (across MSAs) in each year's growth in rents, income, and employment, between 1981 and 2010 for rent and between 1981 and 2008 for income and employment. The cross-sectional dispersion in income and employment growth - the dashed and dotted lines, respectively - is relatively constant over the sample period. The standard deviation in rent growth, by contrast, is higher in the mid- to late 1980s and in the early 2000 s, ahead of the house price peaks in the two booms in our sample period.

The variation in rent growth over the cycles is small relative to the variation in house prices and thus the standard deviation in house prices shown in figure 1.16 must be largely due to changes in the asset pricing of houses across MSAs. In fact, because the increase in variation in rents leads the increase in variation in house prices, purging rent growth from house price growth reveals an even starker pattern of greater dispersion in the changes 


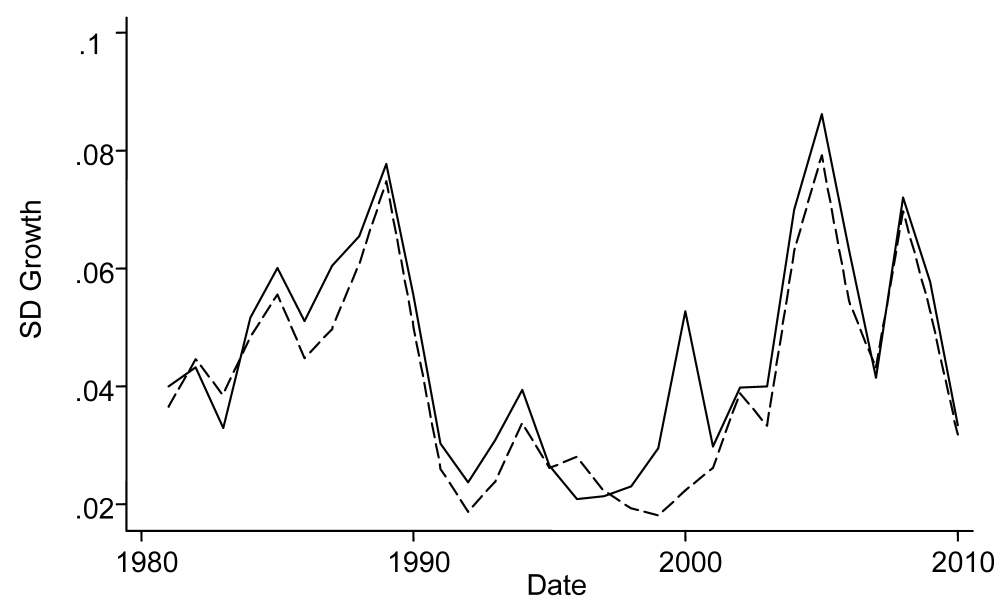

- Std dev of real house price growth ---- Std dev of residual of real HPI growth

Fig. 1.23 Standard deviations of conditional and unconditional annual house price growth

Source: Data comes from Reis and FHFA, deflated by the CPI.

Note: Figure graphs the standard deviations of real house prices and the residuals from an MSA-level regression of real house price growth on real rent growth.

in asset pricing of houses during booms. To demonstrate this, we regressed real house price growth on real rent growth and graphed the standard deviation of the residual by year in the dashed line in figure $1.23 .{ }^{18}$ The solid line repeats the standard deviation of real house price growth from figure 1.16. The standard deviation of annual house price growth net of rent growth increases in house price booms, rises steadily to the house price peaks, and is low in the troughs. It is evident from figure 1.23 that the volatility of house price growth outside of housing booms was due to growth in rents or correlated housing demand fundamentals, whereas the volatility of house price growth inside of housing booms can be attributed to asset pricing factors.

It is worth noting that these patterns cannot be due merely to some MSAs experiencing house price growth in booms and others not. Since the standard deviation increases through the booms, figure 1.23 implies that house price growth must accelerate throughout the boom. Figures 1.24 and 1.25 provide evidence that the entire distribution of house price growth expands in booms. Figure 1.24 plots the distribution of real rent growth by year. The largest dispersion can be found in the mid-1980s and the late 1990s. In the 1983 through 1986 and the 1995 through 2000 periods, the top 75 percent

18. We obtain similar results if we plot the standard deviation of growth in the price-to-rent ratio rather than the residual from the price versus rent regression. The estimated coefficient on rent growth in the bivariate regression of real house price growth on real rent growth is 0.750 with a standard error of 0.054 . 


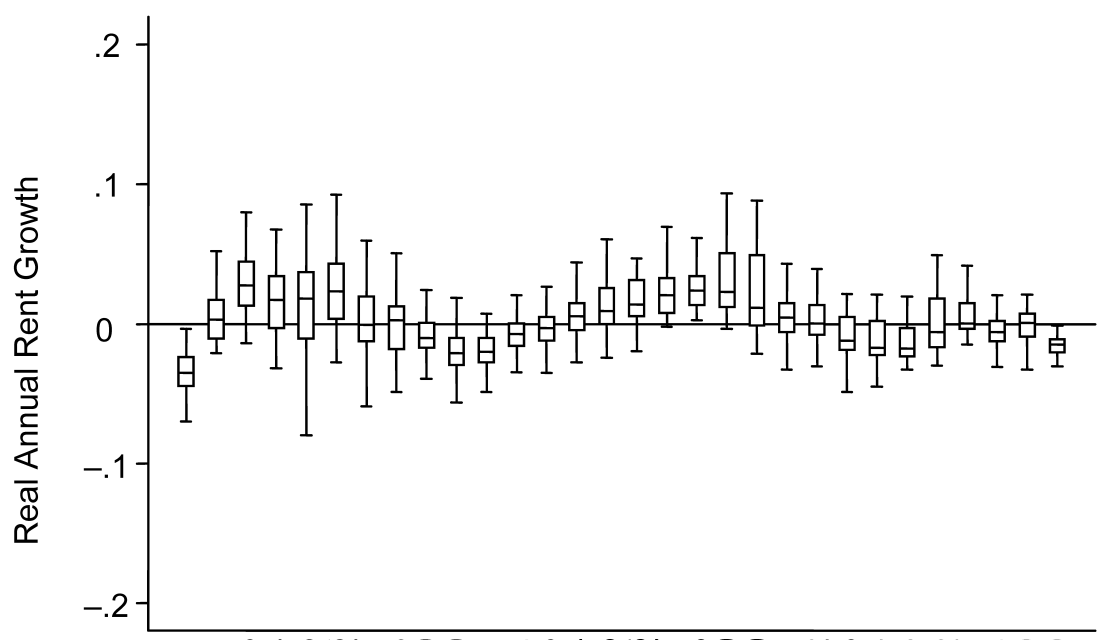

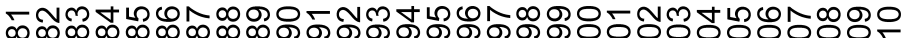
๙

Fig. 1.24 The distribution of annual real rent growth, by year

Source: Data comes from Reis, deflated by the CPI. Excludes outside values.

Notes: Figure plots the distribution of annual rent growth across MSAs in each year. The black-outlined bar runs from the twenty-fifth to the seventy-fifth percentiles. The horizontal black line corresponds to the median.

of MSAs nearly always had positive rent growth. But in the height of the booms of the late 1980s and the mid-2000s, more than 75 percent of MSAs experienced real rent declines. Figure 1.25 plots the distribution of the residuals from the regression of real house price growth on real rent growth. Here, the dispersion was the largest during the booms of the late 1980s and mid-2000s. However, during the peak of the 1980s boom, house price growth conditional on rent growth was much more equally likely to be negative as positive. By contrast, in the run-up to the peak of the 2000s, almost all MSAs in every year between 2001 and 2005 experienced positive house price growth even conditional on rent growth. And, in the subsequent bust, between 2008 and 2010, almost all MSAs experienced declines in the house price growth residual.

The fact that the stylized facts established in this chapter are even more pronounced once demand fundamentals are accounted for suggests that the significant contributor to housing cycles comes from factors that affect the asset pricing of houses. If house price growth and declines were due to a changing desire for having a place to live, or an increase in the amount of housing demanded by households, it would be reflected in rents or incomes. Instead, the cycles must be due to waxing and waning of the taste for owning a house. Potential explanations that are compatible with changing taste for home ownership include credit market factors, such as changes in interest 


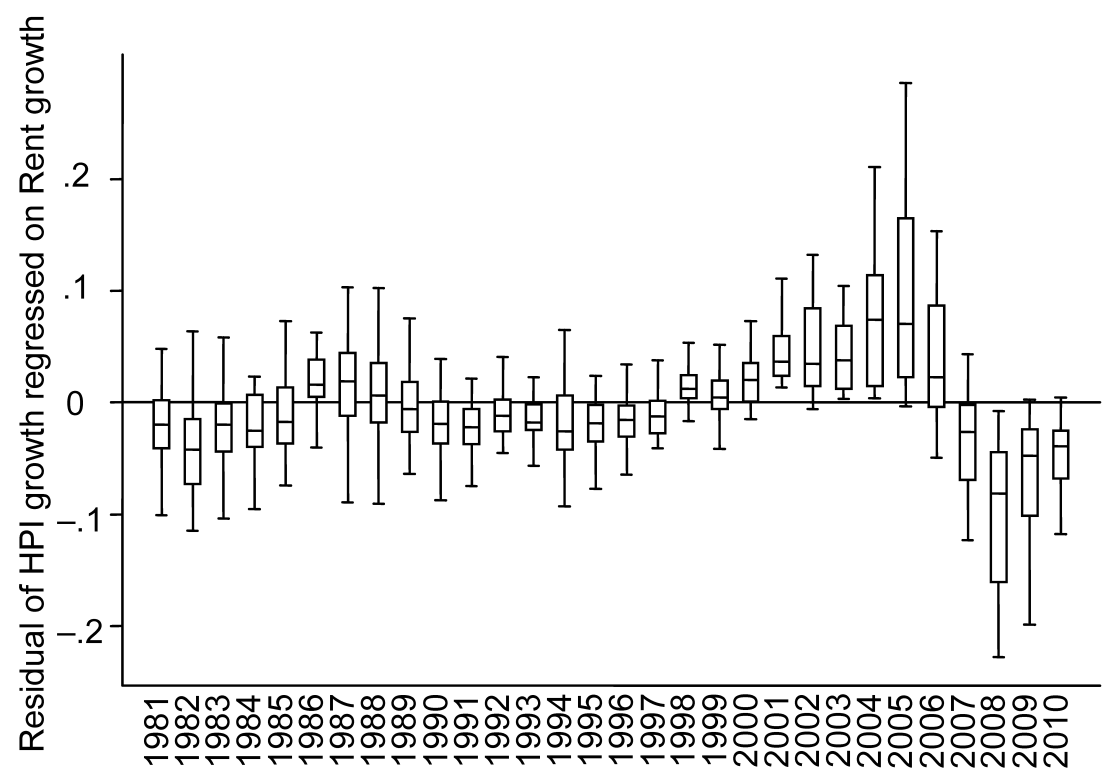

Fig. 1.25 The distribution of conditional annual real house price growth, by year Source: Data comes from REIS and FHFA, deflated by the CPI. Excludes outside values. Notes: Figure graphs the distributions of the residuals from an MSA-level regression of real house price growth on real rent growth. The black-outlined bar runs from the twenty-fifth to the seventy-fifth percentiles. The horizontal black line corresponds to the median.

rates, or changing expectations, such as optimism about house price growth. However, given the empirical patterns documented earlier in this chapter, some of these possibilities are unlikely.

\subsection{Conclusion}

This chapter has documented several empirical patterns in real house prices in the United States over the last three decades. During that span, many housing markets experienced two boom-bust periods in house prices. However, that pattern was far from universal. A large fraction of housing markets had no booms or busts, or just one. Even among cyclical housing markets, the amplitude of house price increases or decreases varied greatly, and the start dates and end dates of each boom were widely dispersed. In addition, during the house price boom-bust of the 1990s and 2000s, nearly all MSAs experienced house price growth during the boom and nearly all MSAs faced house price declines in the bust. In the prior housing cycle, many MSAs faced real house price declines even during the boom and many MSAs experienced real house price growth during the bust. 
Despite these differences across metropolitan areas and between the two housing cycles, there were also considerable similarities along these same dimensions. Housing markets that enjoyed the largest house price booms also faced the largest subsequent price declines. Those MSAs that had the largest boom/bust cycle in the 1980s also typically had the largest cycles in the most recent housing episode, though much of Florida and Phoenix, Arizona are exceptions to that pattern. Neighboring MSAs experienced similar timing and magnitudes of their cycles in the 1990s and 2000s, but not so much in the 1980s.

In addition to these facts about trough-to-peak and peak-to-trough growth rates, annual house price changes became more widely dispersed near the peak of the national house price cycle in both the 1980s and 2000s cycles.

Finally, these patterns persist even when demand fundamentals such as rents, median incomes, or MSA-level employment are netted out of prices. Indeed, controlling for growth in apartment rents makes the boom-bust cycle in house price growth even clearer.

This chapter has been agnostic about the possible causes of house price cycles. However, the accumulation of empirical facts limits the set of feasible explanations. Common national factors cannot easily generate differences in the amplitude of house price cycles across MSAs unless they interact with MSA-specific characteristics and, even then, are hard to reconcile with the variation across MSAs in the start or end date of booms and busts. Potential explanations that depend solely on differences across MSAs in the amount of new housing construction are at odds with the fact that cycles in priceto-rent ratios exhibit the same MSA-level heterogeneity as prices. Even if new construction attenuates house price growth in a given MSA, that new housing supply should also reduce the clearing rent, leaving price-to-rent ratios high. ${ }^{19}$ Other models that emphasize how differences in initial conditions can yield variation in booms and busts across MSAs need to also explain how the cycles in house prices or price-to-rent ratios can repeat over decades within MSAs and why MSAs with similar cycles are located in geographically concentrated clusters. ${ }^{20}$ While much progress has been made on understanding the phenomena of house price booms and busts, it is clear that much work remains to be done.

19. Glaeser, Gyourko, and Saiz's (2008) model sidesteps this issue by incorporating adaptive expectations, so differences across MSAs in the elasticity of supply lead to differences in shortrun growth expectations. Those expectations should be capitalized into the price-to-rent ratio, though their model does not make that explicit.

20. This category of explanations includes "fads," such as Burnside, Eichenbaum, and Rebelo (2011), and subprime mortgages, such as Mian and Sufi (2009), since subprime mortgages were not prevalent in the 1980s. By contrast, Ferreira and Gyourko (2011) speculate that contagion could spread local housing booms to other areas. 


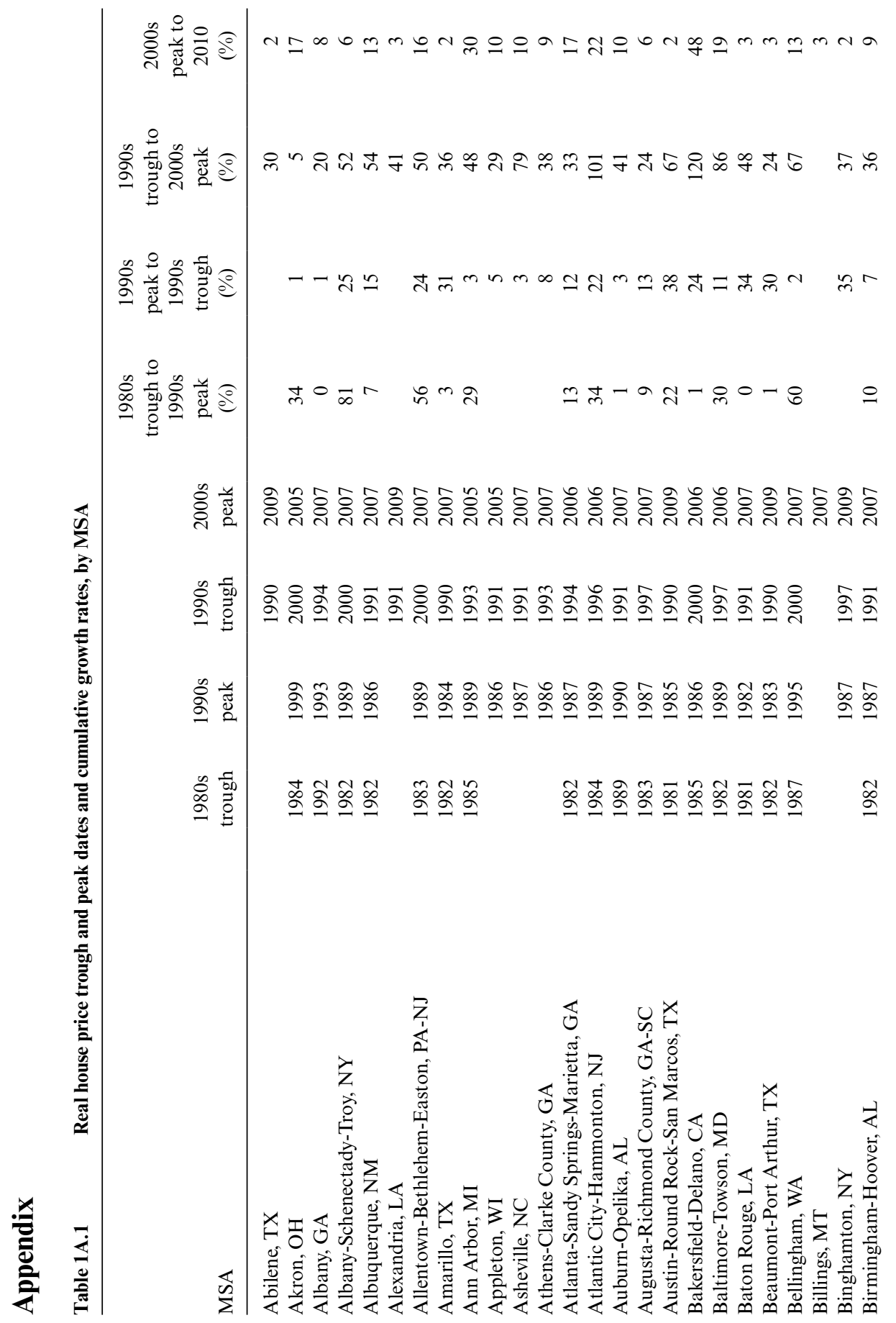




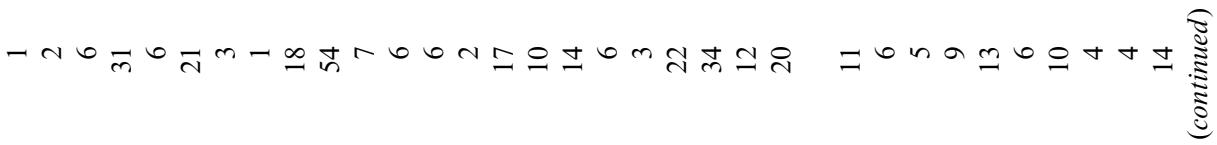

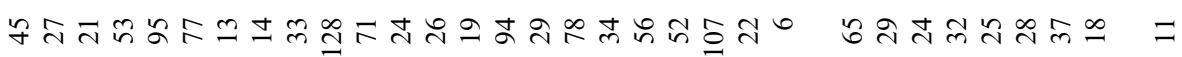

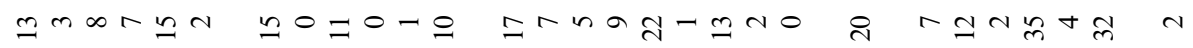

$\infty m$ mmr

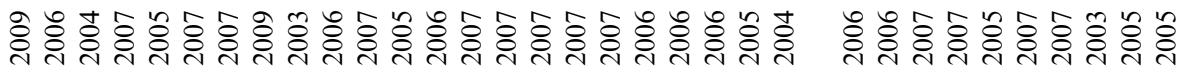

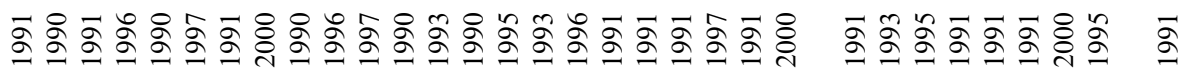

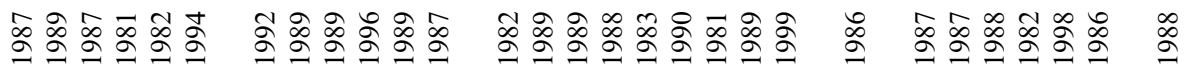

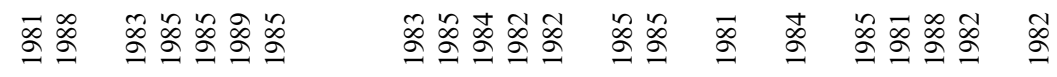

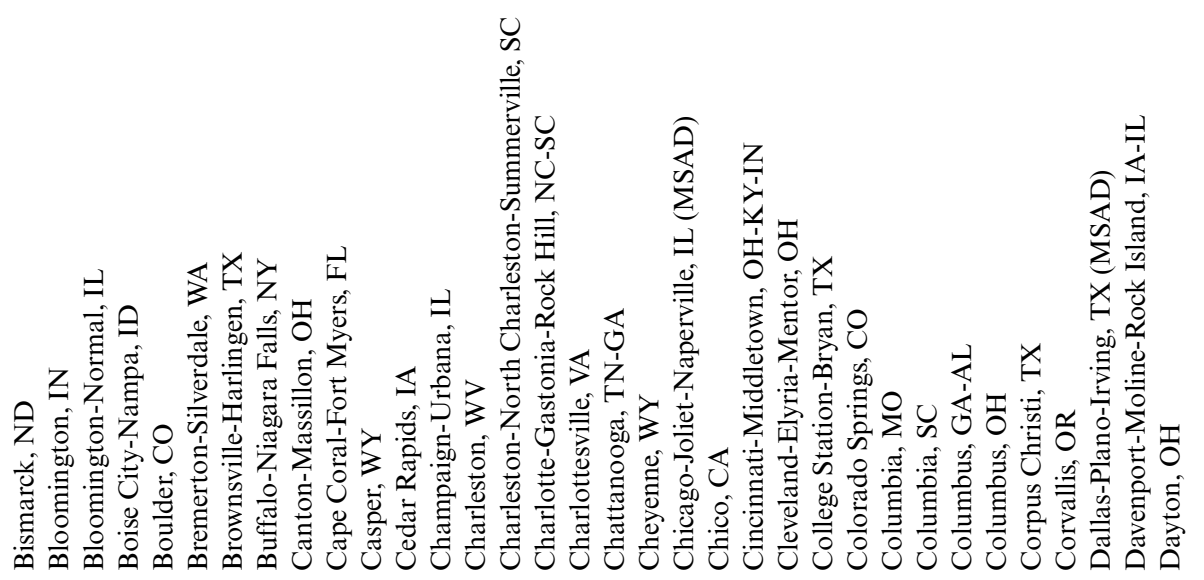




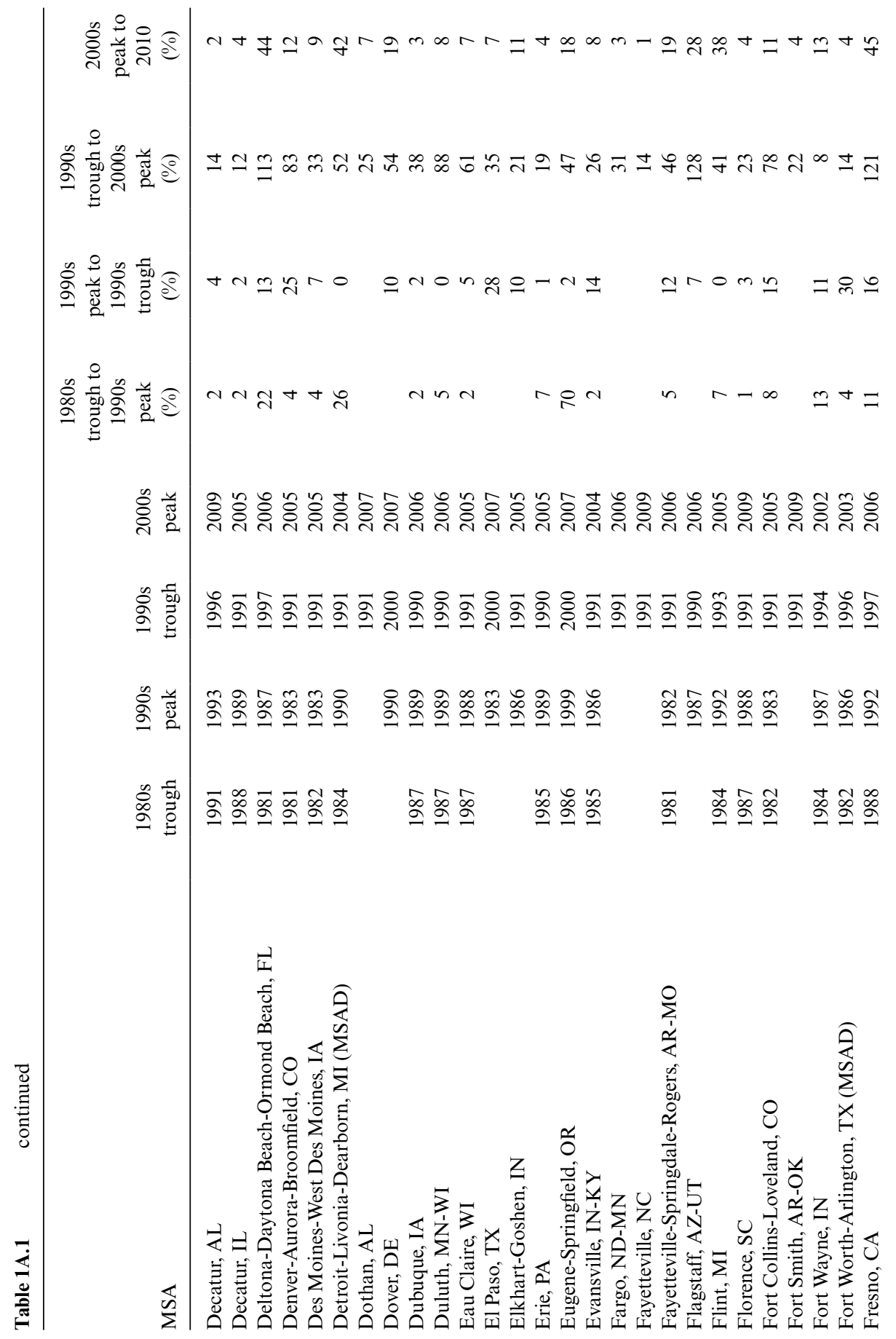




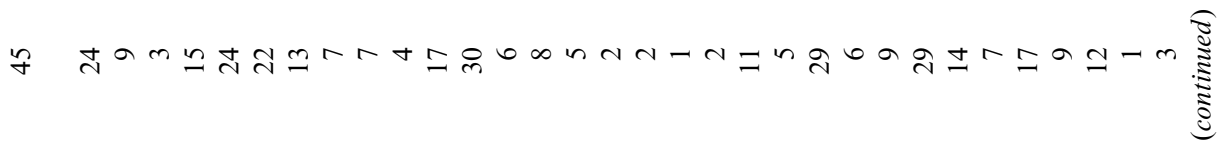

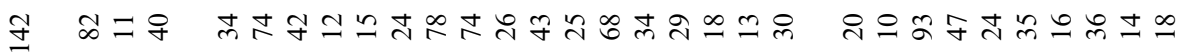

$\because$ In mana이의

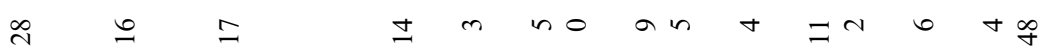

总

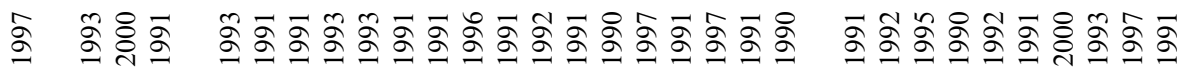

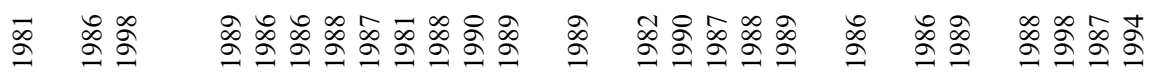

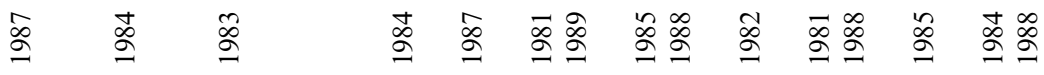

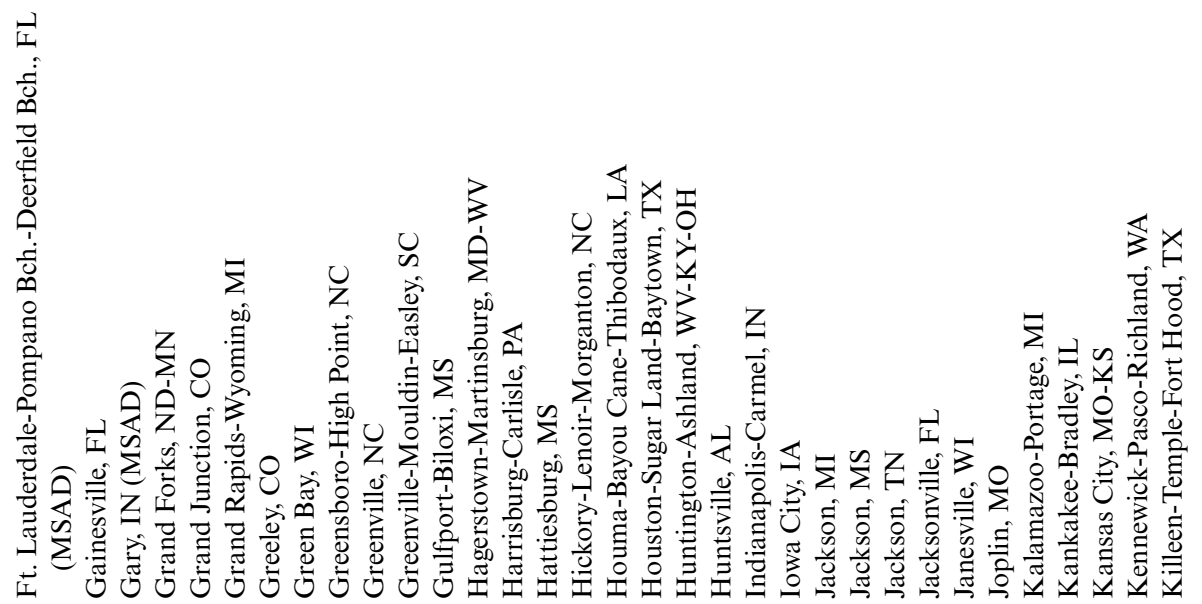




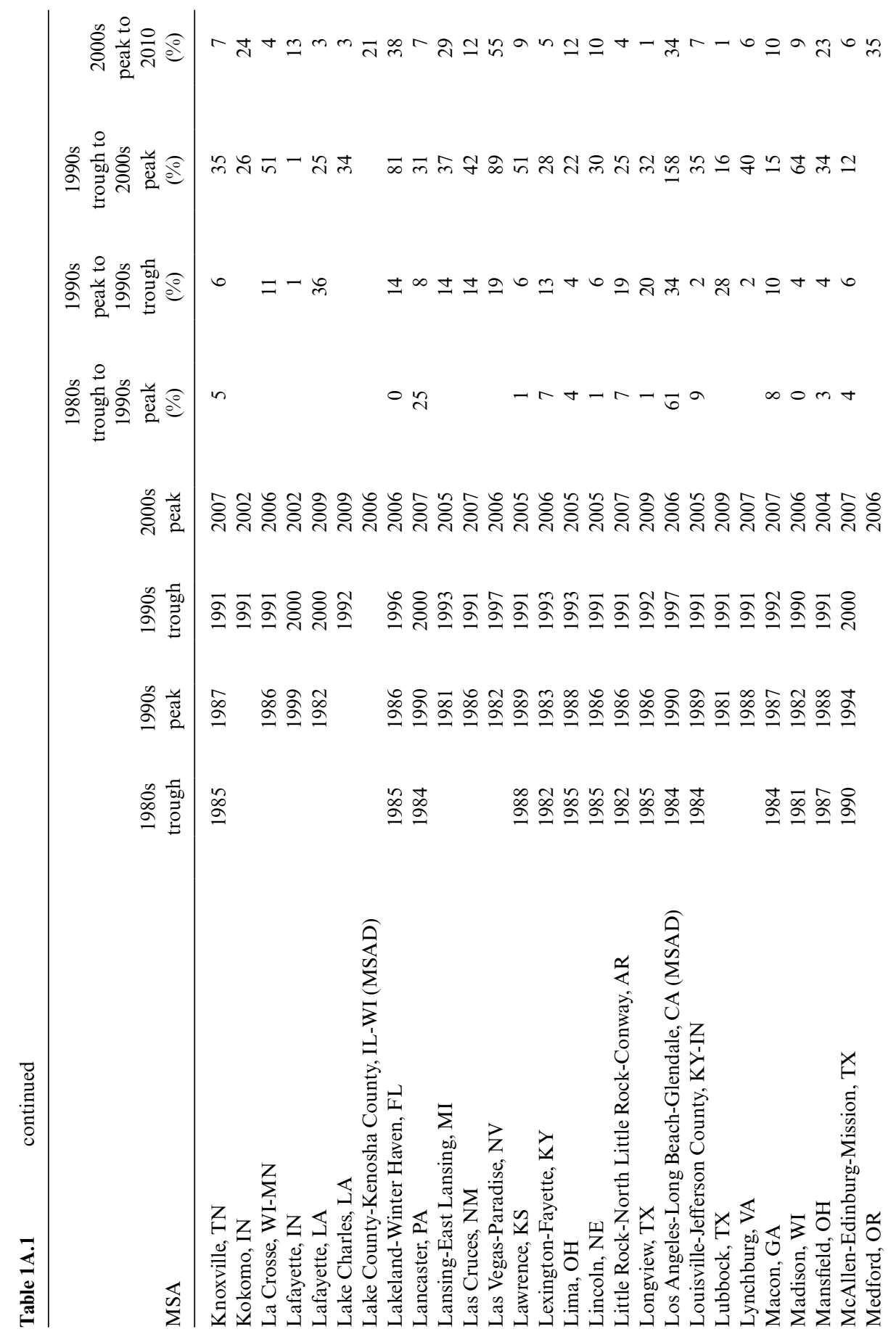




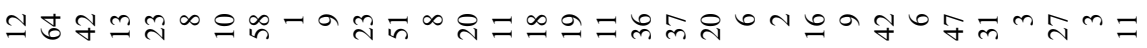

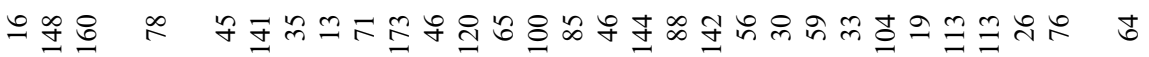

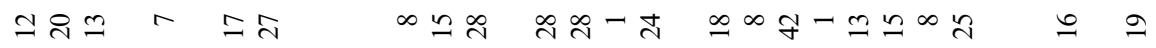

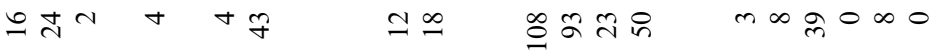

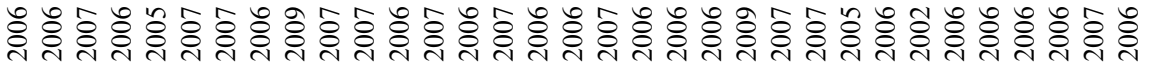

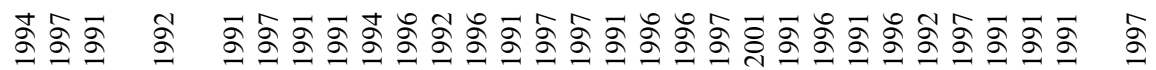

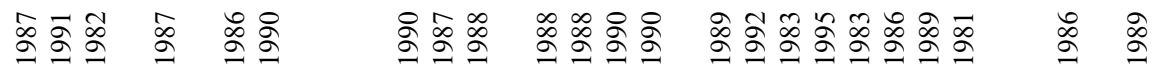

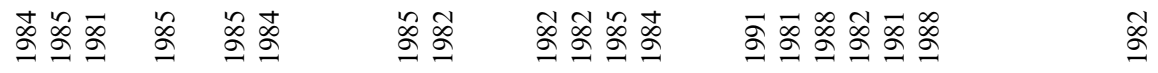

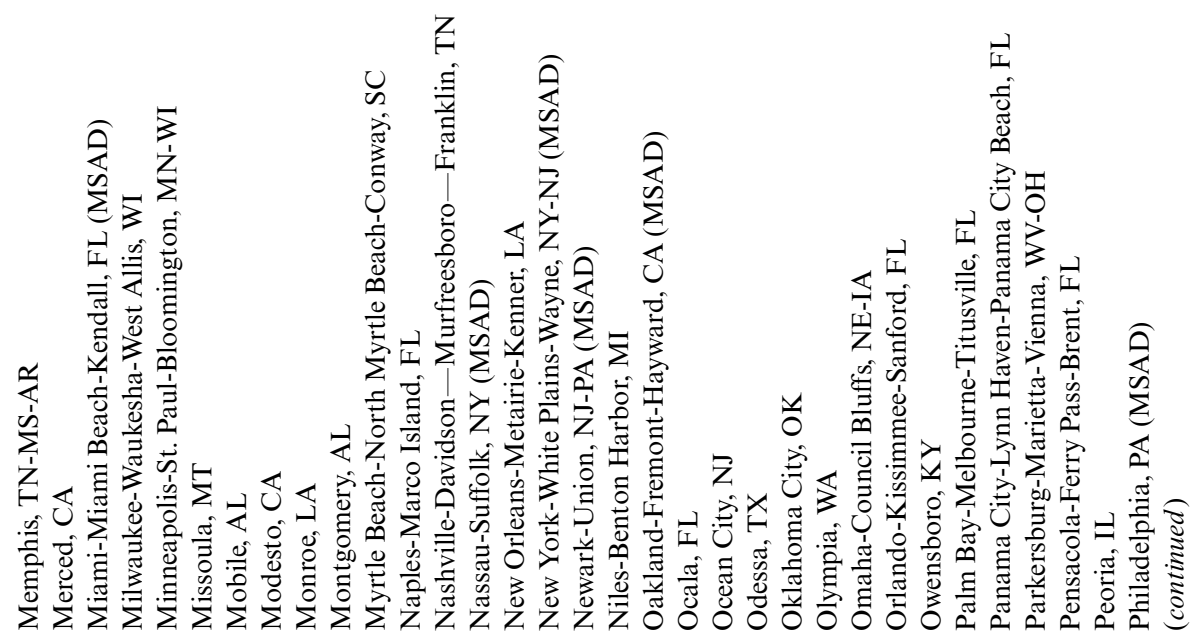




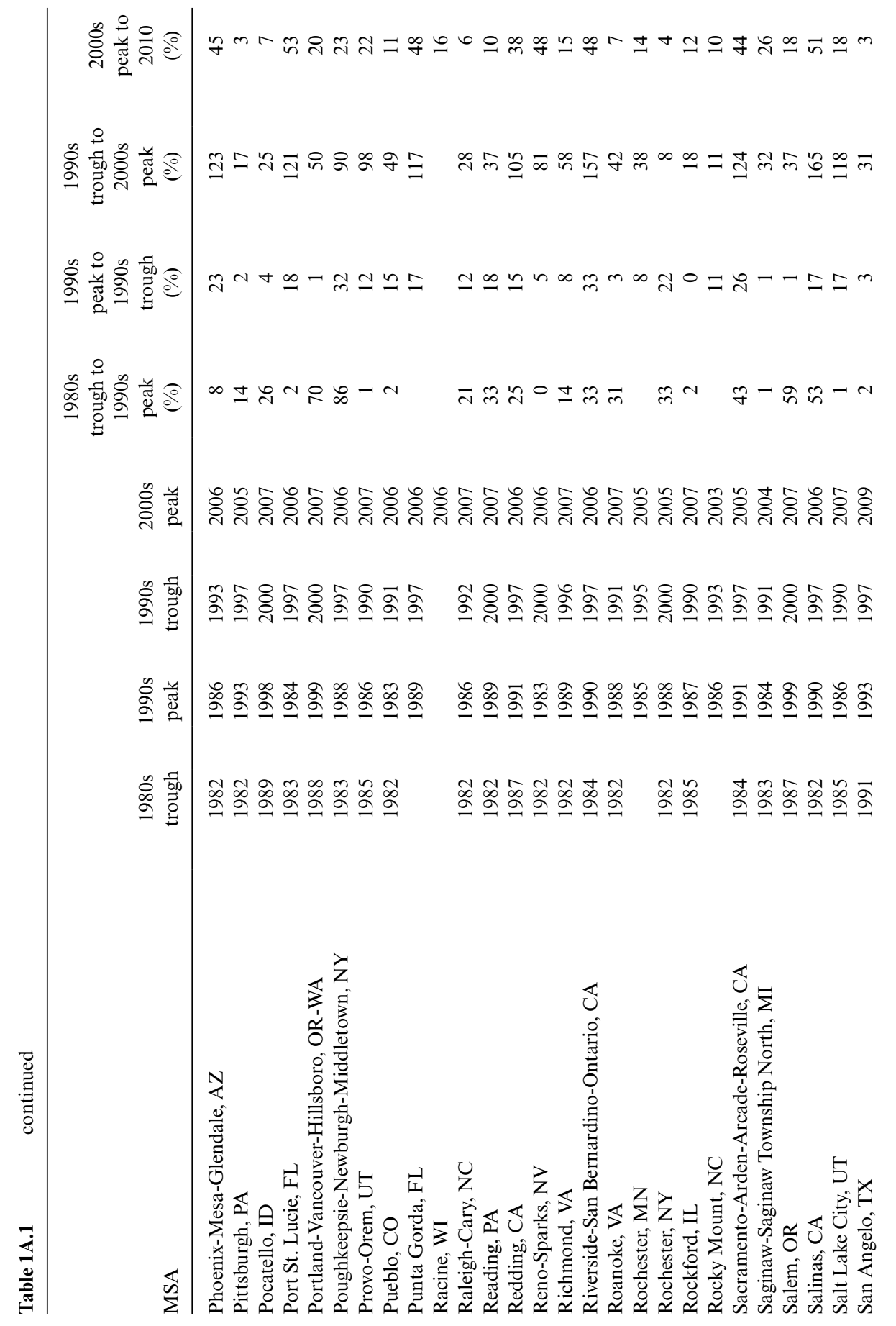




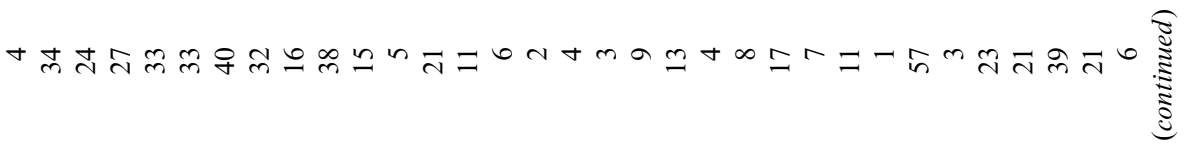

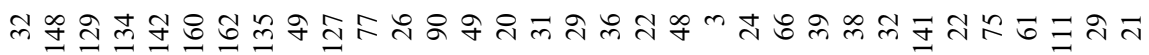

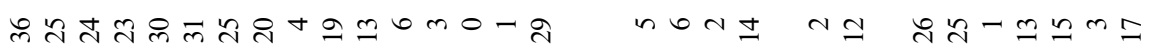

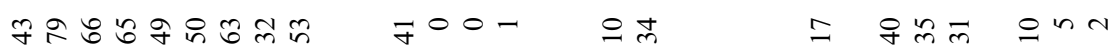

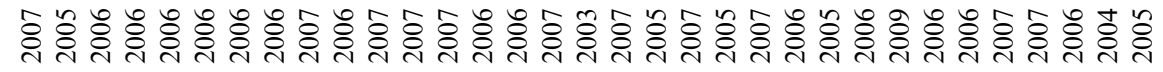

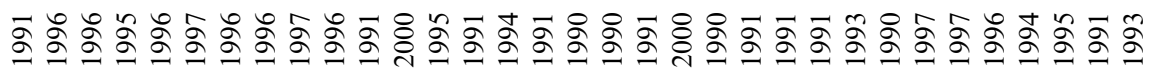

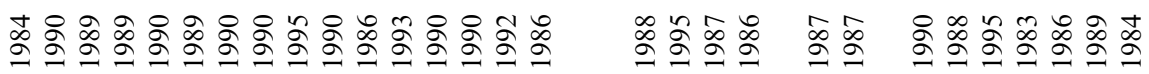

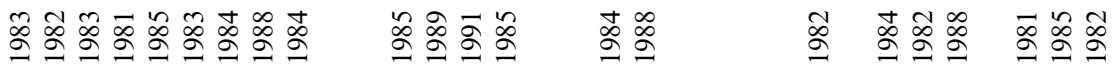

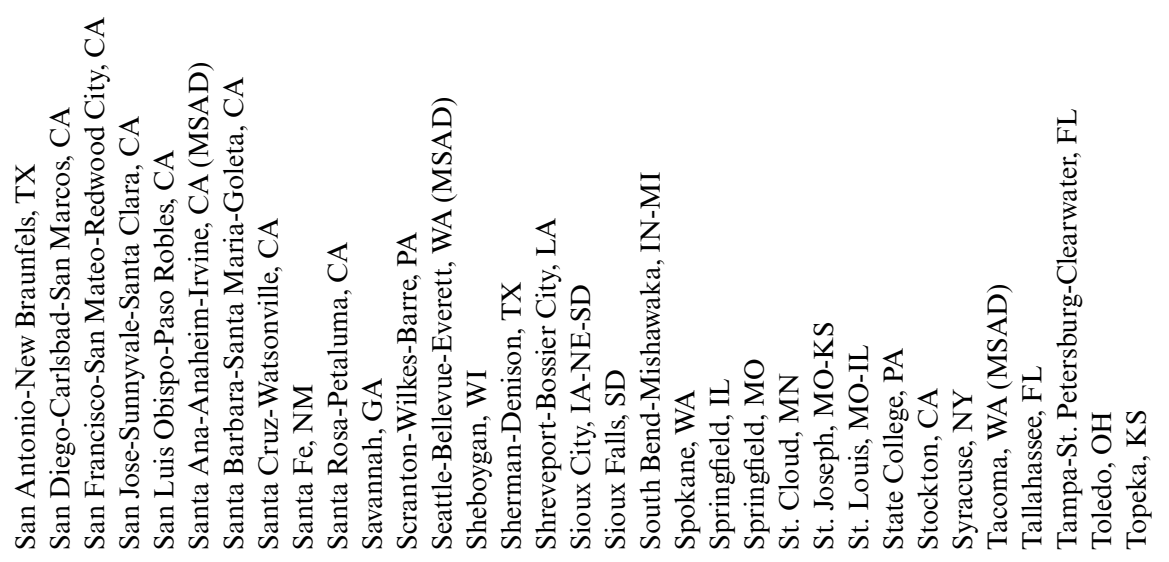




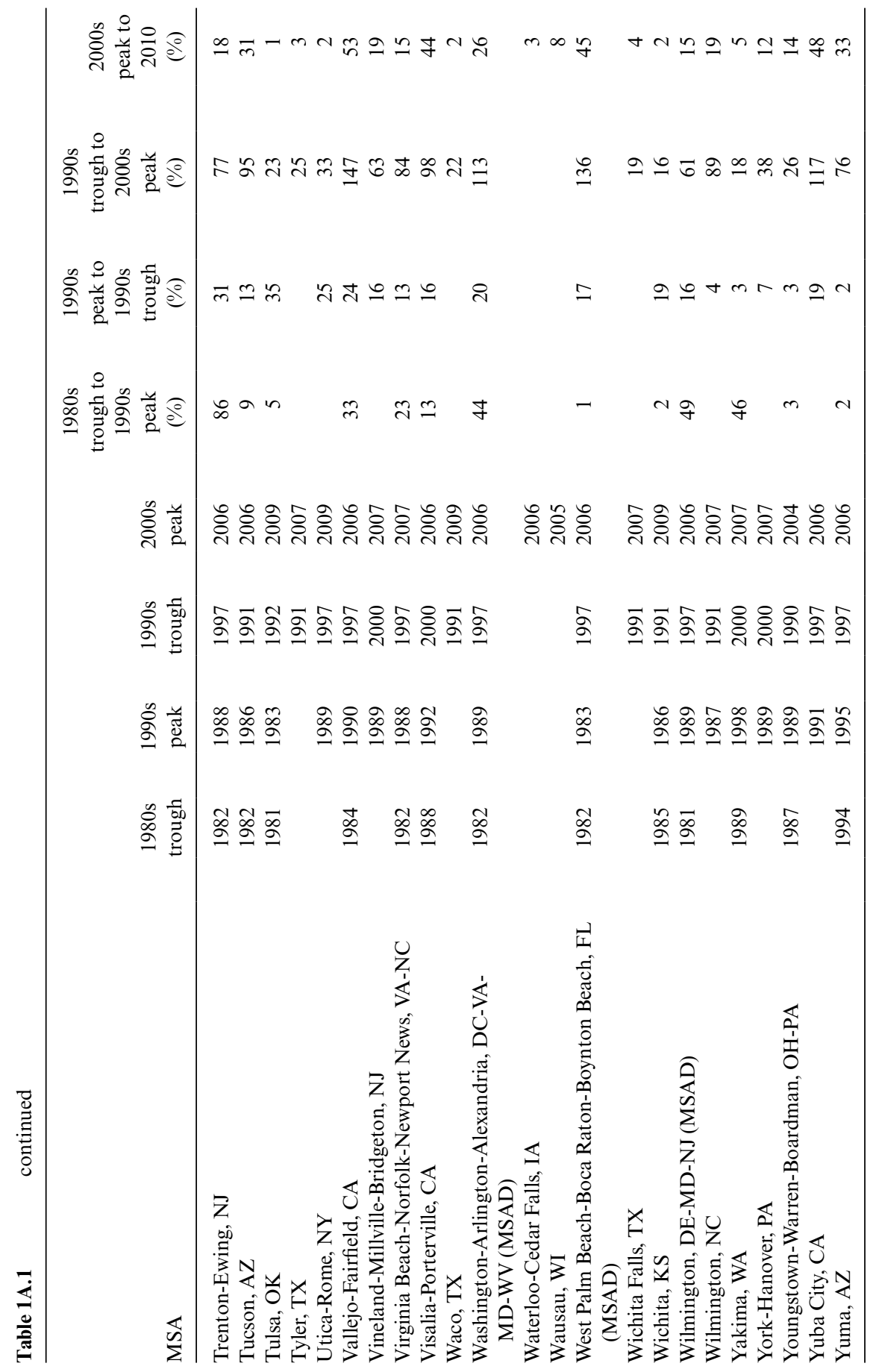




\section{References}

Barlevy, Gadi, and Jonas Fisher. 2011. "Mortgage Choices and Housing Speculation." Federal Reserve Bank of Chicago Working Paper 2010-12, June 15.

Bayer, Patrick, Christopher Geissler, and James Roberts. 2011. "Speculators and Middlemen: The Role of Flippers in the Housing Market."NBER Working Paper no. 16784. Cambridge, MA: National Bureau of Economic Research.

Brunnermeier, Markus, and Christian Julliard. 2008. "Money Illusion and Housing Frenzies." Review of Financial Studies 21 (1): 135-80.

Burnside, Craig, Martin Eichenbaum, and Sergio Rebelo. 2011. "Understanding Booms and Busts in Housing Markets." NBER Working Paper no. 16734. Cambridge, MA: National Bureau of Economic Research.

Campbell, John, Stefano Giglio, and Parag Pathak. 2011. "Forced Sales and House Prices." American Economic Review 101 (5): 2108-31.

Campbell, Sean, Morris Davis, Joshua Gallin, and Robert Martin. 2009. "What Moves Housing Markets: A Variance Decomposition of the Rent-Price Ratio." Journal of Urban Economics 66:90-102.

Case, Karl E., and Robert J. Shiller. 2003. "Is There a Bubble in the Housing Market?” Brookings Papers on Economic Activity 2:299-342. Washington, DC: Brookings Institution.

Cotter, John, Stuart Gabriel, and Richard Roll. 2011. "Integration and Contagion in US Housing Markets.” Working Paper, October 12. Available at SSRN: http:// ssrn.com/abstract=1945975.

Davidoff, Tom. 2012. "Supply Elasticity and the Housing Cycle of the 2000s" Real Estate Economics, forthcoming.

DiPasquale, Denise, and William Wheaton. 1994. "Housing Market Dynamics and the Future of House Prices." Journal of Urban Economics 35 (1): 1-27.

Favilukis, Jack, Sydney Ludvigson, and Stijn Van Nieuwerburgh. 2011. "Macroeconomic Implications of Housing Wealth, Housing Finance, and Limited Risk Sharing in Equilibrium." New York University-Stern Working Paper, January.

Ferreira, Fernando, and Joseph Gyourko. 2011. "Anatomy of the Beginning of the Housing Boom: US Neighborhoods and Metropolitan Areas, 1993-2009."NBER Working Paper no. 17374. Cambridge, MA: National Bureau of Economic Research.

Glaeser, Edward, Joshua Gottlieb, and Joseph Gyourko. 2010. "Can Cheap Credit Explain the Housing Boom?" NBER Working Paper no. 16230. Cambridge, MA: National Bureau of Economic Research.

Glaeser, Edward, Joseph Gyourko, Eduardo Morales, and Charles Nathanson. 2011. "Housing Dynamics." 2011 Meeting Papers, no. 307. Society for Economic Dynamics.

Glaeser, Edward, Joseph Gyourko, and Albert Saiz. 2008. "Housing Supply and Housing Bubbles." Journal of Urban Economics 64:198-217.

Haughwout, Andrew, Richard Peach, John Sporn, and Joseph Tracy. 2011. "The Supply Side of the Housing Boom and Bust of the 2000s." FRBNY Working Paper, November 6. Federal Reserve Bank of New York.

Himmelberg, Charles, Chris Mayer, and Todd Sinai. 2005. "Assessing High House Prices: Bubbles, Fundamentals, and Misperceptions." Journal of Economic Perspectives 19 (4): 67-92.

Lai, Rose, and Robert Van Order. 2010. "Momentum and House Price Growth in the United States: Anatomy of a Bubble.” Real Estate Economics 38 (4): 753-73.

Mayer, Christopher, and Todd Sinai. 2009. "US House Price Dynamics and Behavioral Finance." In Policy Making Insights from Behavioral Economics, edited by 
Christopher L. Foote, Lorenz Goette, and Stephan Meier, 261-95. Boston: Federal Reserve Bank of Boston.

McCarthy, Jonathan, and Richard Peach. 2004. "Are Home Prices the Next 'Bubble'?" FRBNY Economic Policy Review December:1-17.

Meese, Richard, and Nancy Wallace. 1994. "Testing the Present Value Relation for Housing Prices: Should I Leave My House in San Francisco?" Journal of Urban Economics 35:245-66.

Mian, Atif, and Amir Sufi. 2009. "The Consequences of Mortgage Expansion: Evidence from the US Mortgage Default Crisis." Quarterly Journal of Economics 124 (4): 1449-96.

Ortalo-Magné, Francois, and Andrea Prat. 2010. "Spatial Asset Pricing: A First Step.” CEPR Discussion Paper no. 7842. London: Center for Economic Policy Research.

Pavlov, Andrey, and Susan Wachter. 2009. "Subprime Lending and Real Estate Prices." Real Estate Economics 39:1-17.

Robinson, Breck, and Richard Todd. 2010. "The Role of Non-Owner-Occupied Homes in the Current Housing and Foreclosure Cycle." Federal Reserve Bank of Richmond Working Paper no. 10-11, May.

Shiller, Robert. 2005. Irrational Exuberance, 2nd ed. Princeton, NJ: Princeton University Press.

_ 2006. "Long-Term Perspectives on the Current Boom in Home Prices." The Economists' Voice 3 (4): 4.

Smith, Gary, and Margaret Hwang Smith. 2006. "Bubble, Bubble, Where's the Housing Bubble?" Brookings Papers on Economic Activity 1:1-63. Washington, DC: Brookings Institution.

Wheaton, William, and Gleb Nechayev. 2008. "The 1998-2005 Housing 'Bubble' and the Current 'Correction': What's Different This Time?" Journal of Real Estate Research 30 (1): 1-26. 